\title{
WestVirginiaUniversity
}

THE RESEARCH REPOSITORY @ WVU

Graduate Theses, Dissertations, and Problem Reports

2012

\section{Psychosocial Concerns in Pediatric Obstetric Brachial Plexus Injury Patients}

Janelle M. Mentrikoski

West Virginia University

Follow this and additional works at: https://researchrepository.wvu.edu/etd

\section{Recommended Citation}

Mentrikoski, Janelle M., "Psychosocial Concerns in Pediatric Obstetric Brachial Plexus Injury Patients" (2012). Graduate Theses, Dissertations, and Problem Reports. 3545.

https://researchrepository.wvu.edu/etd/3545

This Thesis is protected by copyright and/or related rights. It has been brought to you by the The Research Repository @ WVU with permission from the rights-holder(s). You are free to use this Thesis in any way that is permitted by the copyright and related rights legislation that applies to your use. For other uses you must obtain permission from the rights-holder(s) directly, unless additional rights are indicated by a Creative Commons license in the record and/ or on the work itself. This Thesis has been accepted for inclusion in WVU Graduate Theses, Dissertations, and Problem Reports collection by an authorized administrator of The Research Repository @ WVU. For more information, please contact researchrepository@mail.wvu.edu. 
Psychosocial Concerns in Pediatric Obstetric Brachial Plexus Injury Patients

Janelle M. Mentrikoski

\begin{abstract}
Thesis submitted to the Eberly College of Arts and Sciences

at West Virginia University

in partial fulfillment of the requirements

for the degree of
\end{abstract}

Masters of Science
in
Psychology

Christina L. Duncan, Ph.D., Chair Aaron Metzger, Ph.D.

Tracy Morris, Ph.D.

Department of Psychology

Morgantown, West Virginia

2012

Keywords: Obstetric brachial plexus injuries, psychosocial concerns, pediatric Copyright 2012 Janelle M. Mentrikoski 


\title{
ABSTRACT \\ Psychosocial Concerns in Pediatric Obstetric Brachial Plexus Injury Patients
}

\author{
Janelle M. Mentrikoski
}

Obstetric brachial plexus injuries (OBPI) occur during childbirth when the child's shoulder blade gets stuck on the mother's pubic bone, resulting in damage to nerves in the child's shoulder. Due to the possible visible nature (e.g., injured arm may be shorter than the non-injured arm) and mobility limitations (e.g., difficulties in raising the injured arm to brush one's teeth) associated with these injuries, youth with OBPI may experience psychosocial difficulties. However, little research has examined the psychosocial functioning in this population. The current study sought to investigate possible predictors of social functioning and self-concept in youth with OBPI. This study also explored the utility of a brief screening questionnaire (Brachial Injury Social Questionnaire) specifically designed to assess social difficulties that youth with OBPI may experience. Results suggested that a full model of variables (i.e., perceived social support from parents, classmates, close friends, and teachers; frequency of positive coping strategies; and injury severity) significantly predicted self-concept in youth with OBPI. Specifically, more social support from classmates was associated with increases in self-concept. Another model of predictors (i.e., perceived social support from parents, classmates, close friends, and teachers; frequency of positive coping strategies; injury severity; and age) also was found to be associated with youth-reported social difficulties as measured by the Brachial Plexus Social Questionnaire, with higher levels of perceived classmate social support being significantly associated with fewer social difficulties. In addition, the initial psychometric properties of the Brachial Injury Social Questionnaire seemed promising. Based on the results from this study, clinicians and medical teams who work with youth with OBPI should consider peer support when examining the psychosocial functioning of these youth. 


\section{Acknowledgements}

I would like to thank my advisor and chairperson of my committee, Christina Duncan, for all her time and devotion she has given me throughout the duration of this project. My success is largely attributable to her constant support and for that I am very grateful. I would also like to thank Tracy Morris and Aaron Metzger for their time and valuable input as members of my committee. I could not have completed this project without help from Linda Michaud, Allison Allgier, and Emily Louden at Cincinnati Children's Medical Center and Hospitals and Andrea Melanson and Robert Rinaldi at Children's Mercy Hospital. Next, I would like to acknowledge the members of the Pediatric Psychology Lab and the professors in the Department of Psychology who supported me throughout this project. I would also like to acknowledge all the families who participated in this study. Finally, I would not be where I am today without my family, whose support and love have carried me through my first years of graduate school. 


\section{Table of Contents}

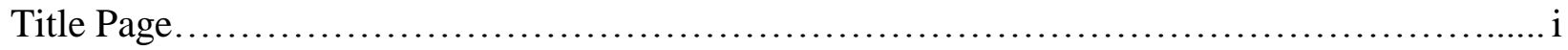

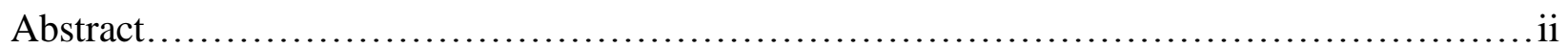

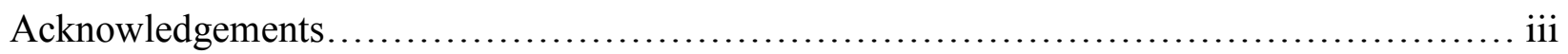

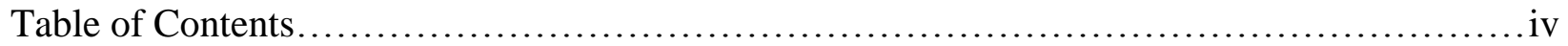

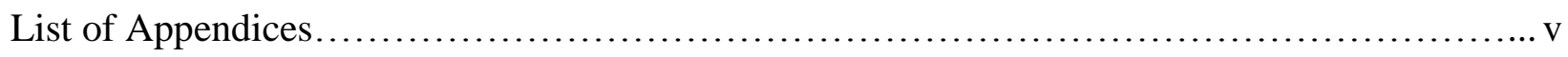

List of Tables....................................................................

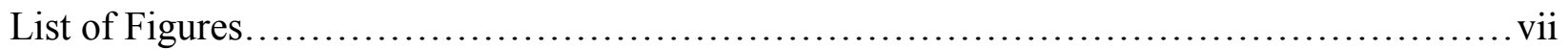

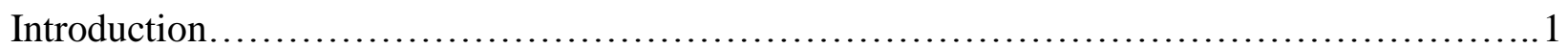

Summary and Rationale............................................... 19

Specific Aims.............................................................. 22

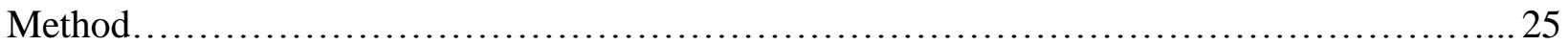

Participants............................................................ 25

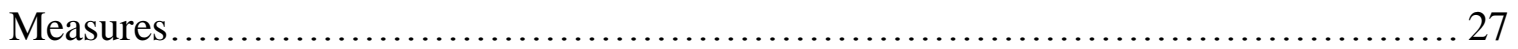

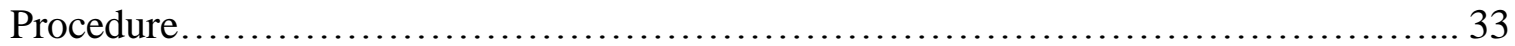

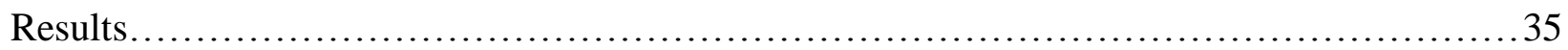

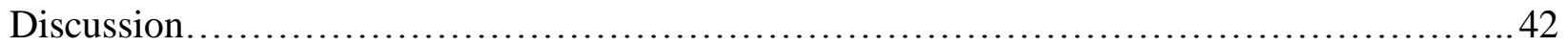

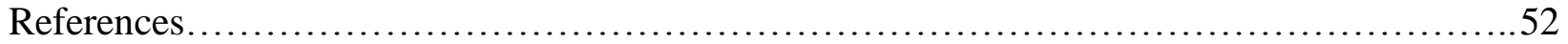

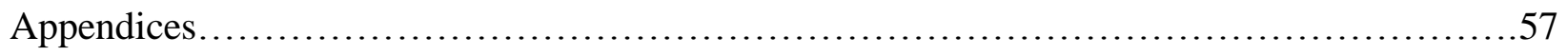

Tables.................................................................... 70

Figures...................................................................... 78 


\section{List of Appendices}

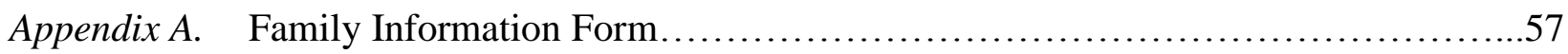

Appendix B. Living with a Chronic Impairment, Parent Version..........................60

Appendix $C . \quad$ Living with a Chronic Impairment, Youth Version...........................64

Appendix D. Brachial Plexus Social Questionnaire, Parent Version..........................68

Appendix E. Brachial Plexus Social Questionnaire, Youth Version.........................69 


\section{List of Tables}

Table 1. Bivariate Associations among Study Variables ............................... 70

Table 2. Means and Standard Deviations of Psychosocial Measures..................... 71

Table 2. $\quad$ Means and Standard Deviations of the Living with a Chronic Impairment-Parent (LCI-P) and Youth (LCI-Y) Versions across Various Samples........................................... 72

Table 3. Means and Standard Deviations of the Social Support Scale for Children (SSSC) Total Domain Scores across Two Samples..................73

Table 4. Means and Standard Deviations of Item Total Scores on The Social Support Scale for Children (SSSC) across Two Samples.

Table 5. Standardized Coefficients $(\beta)$ and Significance Levels ( $\mathrm{p}$-value) for Step Two of the Multiple Regression Analysis: Youth-Reported Social Difficulties from Four Domains of Social Support, Frequency of Positive Coping Strategies, Injury Severity, and Age................................ 75

Table 6. Brachial Plexus Social Questionnaire Parent Version

Item-to-Total Correlations. 76

Table 7. Brachial Plexus Social Questionnaire Youth Version Item-to-Total Correlations................................................ 77 


\section{List of Figures}

Figure 1. Demonstration of Potential Interaction between Age and Perceived Social Support from Parents on Youth-Reported Social

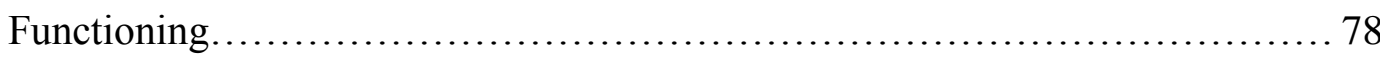




\section{Psychosocial Concerns in Pediatric Obstetric Brachial Plexus Injury Patients}

Children with chronic physical disabilities may be at risk for psychological

maladjustment. Indeed, previous studies have documented some psychological concerns in children with these disabilities (e.g., Lavigne \& Faier-Routman, 1992; 1993). However, one population with chronic physical disabilities that has been understudied is children with obstetric brachial plexus injuries. According to the United Brachial Plexus Network (UBPN, 2011), obstetric brachial plexus injuries (OBPI) occur in every two to five live births out of 1000 in the United States, when the infant's shoulder gets caught on the mother's pubic bone during childbirth, resulting in shoulder dystocia. The injury to the shoulder damages the nerves that control the majority of muscles in the arm, including muscles involved in movement of the fingers, wrist, hand, arm, and/or shoulder (UBPN, 2011). Severity of the injury can vary widely from partial to full paralysis, with some children sustaining injuries that are temporary while others have injuries that require life-long care (UBPN, 2011). OBPI result in mobility impairments that lead to difficulties in everyday tasks that require the use of the injured arm (UBPN, 2011), such as getting dressed or brushing one's hair. In addition to the mobility impairments, individuals with OBPI tend to have visible differences from their healthy peers, such as the injured arm being shorter than the non-injured arm, protrusion of the shoulder blade on the affected side ("winging"), and/or muscle atrophy in the arm due to nonuse (UBPN, 2011). Treatment for these types of injuries can include multiple surgeries to correct the nerve damage, as well as regularly scheduled clinic visits to an occupational or physical therapist (UBPN, 2011).

Because of the mobility impairments and the potentially visible physical differences from healthy children, youth with OBPI may be at risk for psychosocial maladjustment, but very few 
studies have examined the psychological adjustment of these children. Within the context of various models of social support and coping in children with physical disabilities, the current study will explore the relation of several variables (i.e., perceived social support, coping strategies, and severity of injury) to social functioning and self-concept in youth with OBPI.

\section{Models of Social Support and Coping in Children with Physical Disabilities}

\section{Perceived Social Support}

The construct of perceived social support can be defined as one's cognitive appraisal of the availability of support from others (Barrera, 1986). Rather than focusing on the number of people who provide social support for an individual, this conception of social support highlights how the perception of available and adequate social support systems can influence social functioning (Barrera, 1986). One model of perceived social support can be described as a stress prevention model, in that perceived social support can act as a protective factor and decrease the chances that events are perceived as highly stressful, thus reducing the amount of distress experienced by an individual (Barrera, 1986). This general conceptualization of perceived social support can be applied to youth with OBPI. Specifically, youth with OBPI might be at risk for encountering many stressful life events in relation to their injuries, such as difficulties in performing everyday tasks, having to go through potentially painful surgeries and physical therapies, and having to deal with the social stigma of having an injury that can limit mobility and activities, as well as potentially cause visible abnormalities. It can be hypothesized that social support might act as a protective factor in youth with OBPI who perceive more available and adequate social support systems. If this were the circumstance for youth with OBPI, they might perceive potentially stressful life events as less threatening and therefore experience less distress or maladjustment as a result. 
Additionally, as Varni and colleagues noted (Varni, Setoguchi, Rappaport, \& Talbot, 1992), there might be various domains of perceived social support (i.e., derived from parents, teachers, friends, or classmates) that can be associated with social functioning. Based on the model of social support described by Barrera (1986) and the four domains of social support (Varni et al., 1992), the relation between perceived social support and social functioning might vary depending on a variety of factors. Developmental age, in particular, might be one factor that influences how youth perceive social support, especially during adolescence. For example, perceived social support from parents might decrease as children age, given that the peer group tends to become a more important source of influence and social support during adolescence. Early developmental research has generally confirmed this notion and early research and theories have suggested that during adolescence, peer influence tends to peak while parent influence tends to decrease (e.g., Berndt, 1979). As another example, one recent study suggested that perceived social support varies throughout adolescence, in that 9- to 15-year olds tended to rate parents and friends as providing equal levels of social support whereas 16- to 18-year olds tended to rate friends as providing higher levels of social support compared to parents (Bokhorst, Sumter, \& Westenberg, 2010). In addition, this study suggested that perceived social support from classmates were rated as equally supportive as parents in 16- to 18-year olds, suggesting that classmate support also becomes increasingly important as adolescents age (Bokhorst et al., 2010).

In addition, life stressors can be associated with varying levels of perceived social support in youth. For instance, youth with OBPI might have certain life stressors associated with their injuries (e.g., multiple surgeries, wearing braces on their injured arm, limited participation in physical activities, etc.) that require the use of different domains of perceived social support to 
manage any potentially negative effects of these stressors. Thus, exploring specific domains of perceived social support in a sample of youth with OBPI is justified, as it is not yet known whether these youth utilize particular sources of social support to help them adjust and adapt to their injuries. It will also be important to explore if perceived levels of social support from parents and classmates vary as a function of age in youth with OBPI, given aforementioned agerelated effects in previous research (e.g., Bokhorst et al., 2010).

\section{Coping}

Coping with an injury such as OBPI may be particularly difficult for some children and adolescents, due to the nature of the injury. One model, known as the Disability-Stress-Coping Model, explains the adaptation of children with chronic health conditions. This model was first proposed by Wallander, Varni, Babani, Banis, and Wilcox (1989) and further explained by Wallander and Varni $(1992 ; 1998)$. In their model, the authors propose that there are various risk and resistance factors that can contribute to overall adaptation and social functioning. The risk factors included in this model are disability factors (e.g., diagnosis, disability severity, medical problem, bowel/bladder control, visibility, cognitive functioning, brain involvement), lack of independence as a result of the disability, and psychosocial stressors (disability-related problems; major life events; daily hassles; other complications related to mobility impairment such as surgeries, physical therapy, etc.; Wallander \& Varni, 1992). It is thought that these risk factors may be associated negatively with adaptation (i.e., mental health, social functioning, and/or physical health) in youth with physical disabilities (Wallander \& Varni, 1992). The resistance factors in this model include positive intrapersonal factors (e.g., temperament, competence, problem solving ability), social-ecological factors (e.g., family environment, social support, family member's adaptation, utilitarian resources), and stress processing (cognitive appraisal and 
coping strategies; Wallander \& Varni, 1992). It is thought that the intrapersonal factors and the social-ecological factors influence stress processing, which in turn influences adaptation; therefore, the intrapersonal factors and social-ecological factors indirectly impact adaptation (Wallander \& Varni, 1992). Additionally, the resistance factors are believed not only to influence adaptation indirectly but also moderate some of the negative effects of the risk factors (Wallander \& Varni, 1992). For example, a social-ecological factor of social support might offset some of the negative effects of a psychosocial stressor, such as having to endure painful surgeries and/or physical therapy.

According to Wallander and Varni (1998), it is important for studies to consider the various risk and resistance factors outlined in the Wallander et al. (1989) model individually in order to understand further their role in adaptation and social functioning. This model was originally developed to be used with children who had a variety of physical disabilities and chronic illnesses. Taking this idea into consideration, certain factors of this model can be applied to youth with OBPI. The risk factor of disease/disability parameters is relevant, as children and adolescents with OBPI have varying levels of severity and this variation may have a differential association with their social functioning. Additionally, the tendency for OBPI to be visible and to impact physical activity (e.g., participation in sports) adds a unique concern to this population of youth that also could be associated with their social functioning. Furthermore, the resistance factors of social-ecological (e.g., social support) and intrapersonal factors (e.g., self-concept), as well as stress processing, are all relevant to OBPI and how it plays out in children's daily functioning. According to Barrera (1986), perceived social support also can be considered a factor that may moderate the negative effects of psychosocial stressors or assist in one's ability to process stress. Additionally, based on the Wallander et al. (1989) model, self-concept can be 
considered a factor that might correlate with an individual's social functioning. In youth with OBPI, their self-concept might be associated with how well they are able to adapt to their injury as well as correlate with how well they are able to handle various psychosocial stressors. Another resistance factor that may be associated with the ability of youth with OBPI to process stress is their coping strategies. Based on the Wallander et al. (1989) model, if youth with OBPI have adequate coping strategies, they may experience less distress and better adaptation to their injury.

As the Wallander et al. (1989) model demonstrates, there are many variables that may constitute various risk and resistance factors when adapting to chronic health conditions or disabilities. One factor not explicitly analyzed in this model is the possible influence of gender on the coping strategies that youth with disabilities utilize. It may be that gender moderates the use of coping strategies in youth who are coping with disabilities. For example, in one study which included children with chronic pain, it was found that girls tended to use more social support methods to cope with their chronic pain while boys tended to use behavioral distraction techniques (Lynch, Kashikar-Zuck, Goldschneider, \& Jones, 2007).

Due to the lack of research involving children and adolescents with OBPI, it is not yet known what variables will contribute to these youth's psychological adaptation and social functioning. Therefore, the current study will take a first step in examining a few of these variables (e.g., perceived social support, coping strategies, and severity of limb impairment) outlined in the Wallander et al. (1989) model. In addition, this study will investigate the potential moderating effects of gender on the frequency of positive coping strategies used by youth with OBPI. Though there is a paucity of psychological studies involving children with OBPI, it can be thought that youth with this injury might have psychosocial concerns similar to children with other chronic physical disabilities, particularly those involving upper limbs. Thus, literature 
involving children with similar physical concerns as OBPI has been used as a foundation for devising the present study and will be reviewed in detail.

\section{Factors Related to Social Functioning of Children with Various Physical Disabilities Chronic Physical Disorders/Disabilities: Studies Using Mixed Samples}

In an effort to reach a consensus on findings across multiple studies that examined the psychological adjustment of children with physical disorders, Lavigne and Faier-Routman (1992) conducted a meta-analytic review of 87 studies. Their meta-analysis required that reviewed studies include a sample of youth with a chronic physical disorder or disability and also report outcome measures for overall adjustment, internalizing and externalizing symptoms, or self-concept. Children included in this meta-analysis were between the age of three and 19 years; they had a wide range of chronic physical disorders and disabilities, including asthma, blindness, burns, cardiac disorders, cancer, cerebral palsy, cleft lip/palate, cystic fibrosis, deafness/hearing impairment, diabetes, dwarfism, hypospadias, inflammatory bowel disease, juvenile rheumatoid arthritis, myelomeningocele (spina bifida), neurologic disorders, orthopedic disorders, precocious puberty, and renal disorders. Taking into account the variety of methodologies and physical disorders explored by all 87 studies, the authors first explored broadly if children and adolescents with physical disorders differed psychologically from physically healthy controls. In terms of overall adjustment as rated by parents, teachers, and/or mental health professionals, there was a statistically significant difference for all physical disorders combined in comparison to healthy controls and norms, with a mean effect size of 0.62 , indicating that children with physical disorders tended to have higher levels of total adjustment problems (Lavigne \& FaierRoutman, 1992). Additionally, children combined across all studies seemed to display relatively more internalizing $(M$ effect size $=0.55)$ and externalizing $(M$ effect size $=0.26)$ behaviors 
compared to healthy controls or norms when assessed by parents, teachers, and mental health professionals (Lavigne \& Faier-Routman, 1992).

Furthermore, the results of the meta-analysis revealed that the self-concept of youth with physical disorders and disabilities was significantly lower when compared to groups of healthy children; yet these results were not statistically significant when studies reported comparisons with normative data (Lavigne \& Faier-Routman, 1992). However, it is important to note that there were only a few studies $(n=8)$ included in the meta-analysis that actually utilized normative data for comparisons, and therefore the results could be limited by reduced statistical power. Nevertheless, in light of the conflicting results found by the authors regarding the selfconcept of children with physical disabilities, the importance of conducting more studies that explore self-concept in greater detail is warranted. The authors also suggested that future research should use updated and improved instruments for measuring self-concept in children, as most of the studies included in the meta-analysis utilized the Piers-Harris Self Concept Inventory (Piers, 1984). Indeed, recent updates have been made to the Piers-Harris Self Concept Inventory (Piers-Harris Self Concept Inventory-2 ${ }^{\text {nd }}$ Edition; Piers, Harris, \& Herzberg, 2002), which not only improved the measure, but also made it a more contemporary measure of self-concept.

In another meta-analysis, Lavigne and Faier-Routman (1993) explored specific correlates of psychological adjustment in children and adolescents with chronic physical disorders and disabilities. The 38 studies in this meta-analysis included samples of children or adolescents with chronic physical disorders and disabilities similar to the ones included in the previously described meta-analysis (Lavigne \& Faier-Routman, 1992) and examined risk factors related to overall adjustment. The variables that the studies explored in relation to overall adjustment included severity of disease or disability, parent and family variables (maternal and paternal 
psychological maladjustment, marital/family adjustment or conflict, and family support), life stress, socioeconomic status, age, gender, and various child variables (temperament, selfconcept, coping, and cognitive ability). The results from this meta-analysis indicated that disease severity was significantly correlated with overall adjustment; yet, the correlation was not very strong $(M$ correlation $=.14$; Lavigne $\&$ Faier-Routman, 1993). Variables that were significantly and more moderately correlated with overall adjustment were parent and family variables $(M$ correlation across all family variables $=.30)$ as well as various child variables $(M$ correlation across all child variables $=.47$; Lavigne $\&$ Faier-Routman, 1993). These results indicate that disease severity was not as strong a predictor of overall psychological adjustment compared to parent, family, and child variables. Furthermore, the results suggest that variables other than the severity of the disease, such as the child's self-concept and coping strategies, might be important variables to consider when examining the psychological adjustment in children with various physical disorders and disabilities (Lavigne \& Faier-Routman, 1993).

Since the publication of these meta-analyses nearly 20 years ago, a few studies have reported psychosocial functioning with more recent samples. Two studies conducted by Jemta and colleagues (2007; 2009) explored psychosocial factors in children and adolescents with mobility impairments. In the first study, the authors collected data on well-being and coping strategies from 133 children and adolescents (ages 7-18 years) with mobility impairments resulting from cerebral palsy, spina bifida, muscle disease, disease/injury in the central or peripheral nervous system, or disease/injury in the skeleton or joints (Jemta, Dahl, Nordahl, \& Fugl-Meyer, 2007). The majority of participants sustained these injuries at birth, making these participants somewhat comparable to children with OBPI. The coping strategies model used in this study had four dimensions, which included active coping, distraction, avoidance, and support 
seeking. Additionally, this study estimated the participants' well-being through the use of a ninepoint visual scale, which included nine different facial expressions to represent various feelings and emotions (Snoopy Scale; Jemta, Dahl, Fugl-Meyer, \& Stensman, 2005). Demographic and disability information, coping strategies (using the Children's Coping Strategies Checklist; Ayers, Sandler, West, \& Roosa, 1996), and overall well-being were collected from all participants via semi-structured interviews. The results from this study indicated that frequency of using various coping strategies did not matter with regard to well-being; rather, if children perceived that their coping strategies were effective, then they were more likely to estimate their overall well-being as higher (Jemta et al., 2007). The results of this study imply that simply perceiving one's coping strategies to be effective might act as a protective factor for psychosocial adjustment in children with mobility impairments.

In the second study (Jemta, Fugl-Meyer, Oberg, \& Dahl, 2009), the authors explored the extent to which self-esteem was associated with overall well-being and coping strategies in 138 children and adolescents (7-18 years of age) with mobility impairments similar to those in their first study (Jemta et al., 2007). Participants were given the Children's Coping Strategies Checklist (Ayers et al., 1996), the same visual scale (Snoopy Scale) as an assessment of overall well-being, and the I Think I Am, a Swedish self-report inventory (Ouvinen-Birgerstam, 1985) to assess self-esteem and social support. The I Think I Am scale included five dimensions of selfesteem: physical characteristics (e.g., appearance, body image), talents and skills, psychological well-being (e.g., anxiety, aggressiveness), relationships with family, and relationships with others (e.g., friends, teachers), as well as a rating of global self-esteem (Ouvinen-Birgerstam, 1985). All questionnaire data, as well as demographic and disability characteristics, were collected from participants in a semi-structured interview conducted by the author. Results from 
this study suggested that children who reported better psychological well-being and more positive social relationships with others tended also to report better perceived overall well-being as measured by the Snoopy Scale (Jemta et al., 2009). This finding highlights how social support may relate to the overall adjustment in children and adolescents with mobility impairment.

Additionally, the authors failed to find any significant relations between the severity of mobility impairment and self-esteem, indicating that the impairment itself might not be related to negative self-esteem (Jemta et al., 2009). Again, this finding corresponds with those from previous studies (e.g., Lavigne \& Faier-Routman, 1993), which have suggested that it might not be the injury or injury severity, per se, that is the major factor in psychosocial adjustment in children with physical disorders and disabilities. Instead, these findings (Jemta et al., 2009) point toward psychosocial factors, such as social support and self-esteem, which may play a larger role in determining overall adjustment and social functioning rather than injury severity. Finally, the authors examined the relation between self-esteem and coping strategies, with the results suggesting that youth who had lower estimations of their physical characteristics (i.e., appearance, body image) used distraction as a coping strategy more so than the other coping strategies assessed (e.g., active, avoidant, or support seeking coping). However, these findings are specific to a Swedish population and may or may not be generalizable to a population of youth with OBPI living within the United States.

\section{Chronic Physical Disabilities/Impairments: Studies Using Specific Samples}

The previously reviewed studies provide some evidence that youth with chronic physical disorders and disabilities may be at risk for psychosocial concerns. However, some of the chronic physical disabilities targeted in the previous studies did not always include disabilities that had mobility impairments and physically visible abnormalities like OBPI. Therefore, a 
closer look at specific samples of children with chronic physical disabilities that involve visibly apparent mobility impairments is warranted, as it is thought that these samples of children will have similar psychosocial concerns as youth with OBPI.

\section{Spinal Cord Injuries}

Similar to research by Jemta and colleagues (2007; 2009), Antle (2004) also explored various factors thought to be associated with the self-worth in Canadian children and adolescents with spinal cord injuries. Eighty-five youth $(M$ age $=15$ years $)$ who either had spina bifida (inherited injury) or spinal cord injury (acquired injury) took part in this study. Both of these types of injuries have some visible component to them (i.e., possible full or partial paralysis requiring the use of a wheelchair, walkers, or braces, etc.) and involve mobility impairment. Though these impairments involve the lower extremity, this study has some relevance to youth with OBPI. Participants in this study were mailed questionnaires, which assessed self-worth (using age-appropriate versions of the Self-Perception Profile; Harter, 1988) and social support (using age-appropriate versions of the Social Support Scale for Children; Harter, 1985). Results showed that there was no difference in levels of self-worth between youth with spina bifida and spinal cord injury, implying that self-worth may not vary as a function of when a physical impairment is diagnosed. However, the authors noted that the lack of significant findings could be due to the small sample size of children with spinal cord injury $(n=83)$ relative to children with spina bifida $(n=147)$ included in this study.

Moreover, Antle (2004) did not find that the self-worth of children with spinal cord impairment varied as a function of injury severity, again providing evidence that it is not the injury itself but rather various psychosocial variables that might be associated with self-worth in children with physical disabilities. In regards to social support, findings from this study (Antle, 
2004) suggested that perceptions of social support from close friends and parents were significantly and positively related to global self-worth, with perceived social support from parents being the strongest predictor of global self-worth. Still, perceived social support from parents only accounted for twelve percent of the variance (Antle, 2004); consequently, there may be other psychosocial variables or other aspects of social support that may better account for the total variance in self-worth.

\section{Burn Injuries}

Burn injuries are a type of physical injury that not only have the potential to limit mobility but also can be visible; therefore these injuries are relevant in comparison to OBPI. Studies have found that various psychosocial variables, such as coping strategies, social support, and self-concept, might be associated with the psychosocial adjustment of children with burn injuries. One study included a sample of 340 individuals who sustained a burn injury as an adult, 42 adults who sustained a burn injury as children, and 145 children with burn injuries (Browne et al., 1985). The child participants were interviewed in the research office or in their homes and completed questionnaires on their coping strategies (Billings and Moos Coping Scale; Billings \& Moos, 1981), participation in recreational and organizational activities (Social and Recreational Activities Scale; Davidson, Bowden, \& Feller, 1981), perceived social support from family, friends, and peers (Social Support Scale; Davidson, Bowden, \& Feller, 1981), adjustment to their illness (Psychosocial Adjustment to Illness Scale; Morrow, Chiarello, \& Derogatis, 1978), and utilization of health services. In addition, the mothers of the child participants completed the Child Behavior Checklist (Achenbach \& Edelbrock, 1983), a screening measure of behavioral functioning in children, and the Family Environment Scale (Moos \& Moos, 1974), a measure of family functioning. The authors defined burn severity as "major" when the burn consisted of at 
least $30 \%$ total body surface area (TBSA) of a second or third degree burn, and as "minor" when the burn amounted to less than $30 \%$ TBSA for second or third degree burn. Results indicated that the behavioral adjustment of child burn survivors did not vary as a function of burn severity; but instead, child burn survivors tended to have lower behavioral adjustment as a function of having poorer maternal adjustment (as assessed by the Family Environment Scale), using avoidant coping tendencies, distancing themselves emotionally, participating in few recreational activities, and having families with less moral and religious identity (Browne, et al., 1985). This again suggests that it is not the severity of the injury that is associated with maladjustment, but rather several different psychosocial factors.

Another study involving pediatric burn survivors $(N=202$ youth, aged 8-18 years) found interesting results concerning their body esteem, which can be considered one component of selfconcept (Lawrence, Rosenberg, \& Fauerbach, 2007). In this study, participants completed the Body-Esteem Scale for Adolescents and Adults (Mendelson, Mendelson, \& White, 2001), a demographics questionnaire, the Perceived Stigmatization Questionnaire (Lawrence, Fauerbach, Heinberg, Doctor, \& Thombs, 2006), and the Social Comfort Questionnaire (Lawrence et al., 2006). Parents were asked to answer questions regarding their child's burn injury (e.g., how old the child was at the time of the burn) and to subjectively rate the visibility and severity of scars. The participants were recruited from burn camps in the United States and questionnaires were completed either independently by the participants and mailed back to the authors or during interviews conducted at camp. Additionally, a comparison group of youth $(N=981,542$ girls, 439 boys) was drawn from a larger comparative sample used in another study by Mendelson, Mendelson, and White (2001) to validate the Body-Esteem Scale for Adolescents and Adults. It is important to note that the comparison group was recruited from English-speaking schools in 
Montreal, Canada, which possibly limits the generalizability of the results when associations are made using the comparative sample.

According to this study, male burn survivors did not have significantly different average body esteem from the comparison group while female burn survivors tended to have higher average body esteem ratings than the comparison group (Lawrence et al., 2007). These findings were not consistent with the authors' hypotheses, which stated that burn survivors were expected to have lower body esteem ratings than a comparison group (Lawrence et al., 2007). However, given the large sample size, the authors mentioned that the significant results from their study could be due to high power and may not be clinically significant. Furthermore, the authors stated that there are no valid cutoff points for the Body-Esteem Scale (i.e., a certain score signifying clinically significant concerns with body esteem) and so determining clinically significant body esteem is not necessarily appropriate when using this scale. Although the majority of participants in this study reported similar or better body esteem than a comparison group, there was still a possibility that some individuals may experience body dissatisfaction. In fact, the results from this study found that a small portion of burn survivors (i.e., $9.4 \%$ of girls and $3.2 \%$ of boys) reported experiencing dissatisfaction with their appearance, as indicated by their low scores on the Body-Esteem Scale (Lawrence et al., 2007). Given the findings from this study, it would be important to explore specific factors associated with body esteem in order to determine why some individuals are satisfied and others are not. The results of this study, which suggest that youth with burn injuries have similar or better body esteem than non-injured peers, contradict that of previous research with burn survivors (e.g., Browne et al, 1985) and other studies of physical disabilities (e.g., Lavigne \& Faier-Routman, 1992). Browne and colleagues (1985) found that certain factors (e.g., avoidant coping strategies) were associated with problems in 
behavioral adjustment in their sample of pediatric burn survivors. Similarly, results from the meta-analysis conducted by Lavigne and Faier-Routman (1992) suggest that youth with physical disorders had lower self-concept and more behavior concerns compared to children without physical disorders. Taken together, these other studies suggest the youth with physical disorders may experience some psychosocial difficulties related to their disorders/injuries. Because of the lack of consistent results among these studies, it would have been interesting to learn what made the sample of children in the Lawrence and colleagues (2007) different and whether particular psychosocial variables (e.g., higher levels of perceived social support and better coping strategies) were acting as protective factors in their adjustment given that the outcome of this study focused solely on body esteem.

\section{Congenital Limb Deficiencies}

Children with congenital limb deficiencies have very similar physical limitations as children with OBPI, in addition to having injuries that also are visible in nature. Varni and colleagues (1992) explored how multiple domains of perceived social support were related to various psychological adjustment factors in children with congenital limb deficiencies. Fortynine children between the ages of eight and 13 with congenital $(n=42)$ and acquired $(n=7)$ limb deficiencies participated in their study. Participants were assessed on measures of depression (Children's Depression Inventory; Kovacs, 1983), trait anxiety (State-Trait Anxiety Inventory for Children; Spielberger, 1973), general self-esteem (Self-Perception Profile for Children; Harter, 1988), degree of limb loss, and perceived social support (Social Support Scale for Children; SSSC; Harter, 1985). Degree of limb loss was defined by the Degree of Limb Loss Scale, which the authors created for the purpose of the study. For this scale, total limb loss was calculated by summing upper and lower body limb loss ratings (Varni et al., 1992). Descriptive statistics for 
the four SSSC domains of perceived social support showed a lot of variability in scores for this sample of children (Varni et al., 1992). Additionally, according to the authors of this study, the SSSC domain scores were comparable to findings with physically healthy children; therefore the following results should be interpreted with some caution.

Multiple hierarchical regression analyses were performed using depressive symptomatology, trait anxiety, and general self-esteem each as outcome variables while demographic factors (age, sex, degree of limb loss) and perceived social support domains (classmate, parent, teacher, and friend) were used as the predictor variables (Varni et al., 1992). The results from this study suggested that the demographic/medical variables were not significantly associated with any outcome measure; however, all the domains of perceived social support were significantly and positively associated with all three outcome variables. When further examining the domains of perceived social support, the authors controlled for the demographic variables and each of the perceived social support domains separately to find that support from classmates was the only significant predictor of all three outcome variables. Another notable finding from the Varni and colleagues (1992) study was that the degree of limb loss was not significantly associated with any of the adjustment outcome variables used in this study. Finally, the authors found that age was significantly and negatively correlated with perceived parent social support only, meaning that younger children tended to perceive more parental social support than older children.

\section{Obstetric Brachial Plexus Injuries}

One of the earliest studies looking at psychological adjustment of individuals with OBPI was a longitudinal study (Adler \& Patterson, 1967). Though this study examined psychological adjustment of individuals with OBPI, the measurement of this construct was unclear. 
Nonetheless, the authors reported that the level of psychological adjustment among the majority of their 88 participants was rated as "excellent" in a follow-up examination, with the time period for follow-up ranging from one to 35 years $(M$ time period $=18$ years $)$. It is unclear how the authors came to this conclusion and also who rated the participants and their psychological adjustment (Adler \& Patterson, 1967). Given that this study is substantially outdated and has unclear methodology, the utility of these results is lacking. However, it is interesting to note that concern for the psychosocial adjustment of individuals with OBPI began as early as the 1960's.

More recently, Strombeck and Fernell (2003) conducted a Swedish study with 51 adolescents (15 to 18 years old) with OBPI. These youth were compared to 116 adolescents without OBPI on measures of attention, school work, leisure time, and self-esteem, as well as open-ended questions regarding perceived abilities, worries, and friends. The measures included questions based on the Anser-System Questionnaire (Isberg \& Kjellman, 1999). Results indicated that self-esteem (defined in terms of participants' self-ratings of perceived abilities in sport or motor activities) in youth with the most severe OBPI was significantly lower compared to the healthy control group. Yet, the results also revealed that the sample of youth with OBPI had similar interests, activities, and social lives to the comparison group. Though this study was the first to investigate psychosocial concerns of youth with OBPI using standardized measures, generalization of findings may be limited by its focus on a Swedish sample and its rather narrow definition of self-esteem (i.e., self-perception of athletic and motoric abilities). Taken together, it is clear that more research needs to be conducted with this under-studied group of children in an effort to understand better their day-to-day concerns. 


\section{Summary of Literature and Rationale for Current Study}

OBPI are sustained during childbirth and result in damage to nerves that control muscle function in the fingers, hand, elbow, arm, and/or shoulder (UBPN, 2011). These injuries lead to mobility impairments that affect functioning in daily life tasks, such as brushing one's teeth and typing on a computer keyboard. In addition to the mobility impairments caused by OBPI, there also tends to be a visible component to this injury, such as the injured arm being shorter than the non-injured arm or atrophied in appearance (UBPN, 2011). Individuals with OBPI not only have to overcome the mobility limitations associated with their injuries, but also have to deal with the possible negative social effects of having a visibly obvious injury or abnormality. The social concerns might be particularly salient for adolescents, who not only manage typical developmental tasks associated with adolescence, but also have to do so with an often obvious chronic physical disability. Indeed, anecdotal clinical evidence suggests that youth with OBPI might be at risk for psychological maladjustment due to the nature of their injury and its implications, but research is needed to investigate these issues. To date, only one study has evaluated psychosocial adjustment in youth with OBPI (Strombeck \& Fernell, 2003) using clear methodology; yet, this investigation involved only Swedish participants and evaluated a somewhat narrow set of psychosocial concerns. Due to the lack of psychological studies involving youth with OBPI, a broader look at relevant literature is required to provide a foundation for this direction in research. In particular, the greatest relevance can be found with psychosocial studies involving samples of youth with injuries generally comparable to OBPI (e.g., congenital limb deficiencies, burn injuries).

Studies examining the psychosocial difficulties of youth across various physical disorders offer a basis for the importance of exploring the psychosocial functioning of youth with OBPI. 
Lavigne and Faier-Routman $(1992 ; 1993)$ conducted meta-analytic reviews of a total of 125 studies examining psychosocial concerns in youth with chronic physical disorders and disabilities. These meta-analyses provided some insight into the complexity of psychosocial concerns that children with chronic physical disorders and disabilities experience, as well as provided some awareness of specific variables that might be important to consider, such as selfconcept and coping strategies, when evaluating youth with OBPI. Results from these studies suggested that children with various physical disorders are at risk for developing difficulties in overall adjustment as well as internalizing and externalizing symptoms (Lavigne \& FaierRoutman, 1992). The results from Lavigne and Faier-Routman (1993) also indicated that parent and family risk factors in addition to child characteristics (e.g., coping, self-concept) are significantly correlated with child adjustment.

Furthermore, the meta-analyses yielded consistent results regarding the severity of the child's physical disability not being a strong predictor of overall adjustment (Lavigne \& FaierRoutman, 1992; 1993). However, one limitation of both of the Lavigne and Faier-Routman metaanalyses is that some of the disabilities included in the studies did not have a combination of mobility impairments and visibly distinct disabilities like OBPI. In addition, samples of children with chronic illnesses were included in the Lavigne and Faier-Routman (1992) meta-analysis. The potential visibility of OBPI adds a unique concern in addition to the limited physical mobility caused by this injury, and thus the conclusions of these meta-analyses may not directly apply to this group of youth.

Studies examining samples of children and adolescents with specific injuries or physical conditions similar to OBPI also provide some insight into particular psychosocial concerns that may be of relevance. For example, a study conducted by Varni and others (1992) highlight how 
the psychosocial variable of perceived social support might serve as a protective factor for children with congenital limb deficiencies. In particular, the authors found that while a full model of all four domains of perceived social support (parent, teacher, classmate, and close friend) was significantly associated with the variance in general self-esteem (with $38 \%$ of the variance being accounted for), perceived classmate social support was the only significant, individual predictor associated with general self-esteem ( $\beta=.556$; Varni et al., 1992).

Additionally, the results from the Varni and colleagues (1992) study suggested that the severity of limb loss was not significantly associated with psychosocial adjustment, indicating again that it is not necessarily the extent of the injury that is associated with psychosocial difficulties.

Due to the close similarity in impairments among children with congenital limb deficiencies and OBPI, the results from the Varni et al. (1992) study are relevant to the current study. While this study demonstrates some evidence for social support as a protective factor, it also is necessary to determine if perceived social support acts as a protective factor in youth with OBPI, in particular. Moreover, it is important to examine if youth with OBPI experience psychosocial difficulties that are associated with the severity of their injury or if results will be comparable to that of Varni et al. (1992). Finally, research from the burn injury literature suggest that protective psychosocial factors, such as adaptive coping strategies as well as perceived social support, might be more important to consider when examining overall adjustment, rather than severity of injury (Browne et al., 1985).

With respect to OBPI in particular, Strombeck and Fernell (2003) were one of the first researchers to explore psychosocial concerns of youth with this chronic condition. The authors recruited a sample of adolescents with OBPI and a sample of normal healthy controls and assessed their participants on a variety of measures related to their social functioning with OBPI. 
Results suggested that youth with the most severe OBPI tended to have significantly lower selfesteem in terms of perceptions of physical abilities when compared to normal healthy controls. However, this study was limited by its methodology used to assess self-esteem. Additionally, the results of this study cannot be directly applied to youth in the United States, as this study was conducted in Sweden. Finally, this study did not examine other psychosocial variables, such as perceived social support and coping strategies, which are considered to be potentially relevant psychosocial variables for examining the social functioning of youth with OBPI.

Given that youth with OBPI might be at risk for psychological maladjustment, as a result of the mobility and visibly apparent impairments associated with this type of injury, the current study will explore different risk and protective factors that might be associated with social functioning. Based on previous models that conceptualized various risk and resistance factors and their relation to the psychological adjustment of children with chronic physical disabilities (Wallander et al., 1989), it is thought that the variables of perceived social support, coping strategies, and severity of limb impairment might play a role in the overall social adaptation and self-concept of youth with OBPI.

\section{Specific Aims and Hypotheses}

Using existing and relevant literature, the present study had five aims.

1. The first aim of this study was to describe the psychosocial functioning of a sample of youth with OBPI and to contrast the descriptive data informally with normative data and data reported in the existing literature. It was hypothesized that youth with OBPI would experience comparable levels of concerns in psychosocial functioning (i.e., social support) similar to that found in youth with congenital limb deficiencies. Additionally, it was hypothesized that overall difficulties in social functioning would be similar to those 
difficulties experienced by youth with various chronic illnesses and injuries. Lastly, it was hypothesized that our sample of youth with OBPI would obtain scores on psychosocial questionnaires that indicate more problematic concerns, when compared to normative means.

2. The second aim of the study was to examine the extent to which perceived social support, frequency of positive coping strategies, and injury severity predicted social functioning in youth with OBPI. It was hypothesized that a full model of predictors (perceived social support from four different domains, frequency of positive coping strategies, and degree of limb impairment) would account for a significant portion of the variance in perceived social functioning in youth with OBPI. It was hypothesized that higher levels of perceived social support and more frequent usage of positive coping strategies would act as protective factors and would therefore predict better levels of social functioning. Given that previous studies suggested that limb impairment was not a strong predictor of social functioning (e.g., Varni et al., 1992), it was hypothesized that this variable will not be as strong of a predictor as the other psychosocial variables explored. However, given the unique nature of OBPI and that there is a lack of research with this sample of youth, it was important to explore limb severity and its relation to social functioning. Moreover, based on existing literature (e.g., Berndt, 1979; Bokhorst, et al., 2010), it was anticipated that age might serve to moderate the relation of perceived social support from parents and classmates with social functioning of youth with OBPI. Also consistent with previous literature (e.g., Lynch et al., 2007), it was anticipated that gender might serve to moderate the relation between frequency of positive coping strategies and social functioning. 
3. The third aim was to investigate the degree to which perceived social support, frequency of positive coping strategies, and injury severity predicted self-concept in youth with OBPI. It was hypothesized that a full model of predictors (perceived social support from four domains, frequency of positive coping strategies, and limb severity) would account for a significant proportion of the variance in self-concept. It was thought that higher levels of perceived social support and more frequent use of positive coping strategies would be associated with higher self-concept. Based on previous research, it was thought that limb severity would not be as strong a predictor of social functioning as the other variables included in this model. Furthermore, similar to Aim 2, it was thought that age might serve to moderate the relation between perceived social support from parents and classmates and self-concept, while gender might serve to moderate the relation between frequency of positive coping strategies and self-concept.

4. The fourth aim of the study was to explore the initial psychometric properties of a brief questionnaire that was created for the purposes of this study. The Brachial Plexus Social Questionnaire was designed to provide information on the specific social and physical concerns of individuals with OBPI and has the potential to be used as a brief screening tool in clinics. It was hypothesized that the measure would have satisfactory levels of internal consistency and would correlate significantly and positively with social functioning scores, the most closely related construct.

5. The fifth and final aim of the study was exploratory and sought to examine the degree to which perceived social support, frequency of positive coping strategies, injury severity, and age predicted social difficulties specific to youth with OBPI. It was hypothesized that a full model of predictors (perceived social support from four domains, frequency of 
positive coping strategies, limb severity, and age) would account for a significant proportion of the variance in OBPI-related social difficulties. It was thought that higher levels of perceived social support, more frequent use of positive coping strategies, and younger age would be associated with fewer OBPI-related social difficulties. Similar to the previous aims, it was thought that limb severity would not be as strong of a predictor as the other variables included in this model. Given the exploratory nature of this aim, age was included in this model as it was hypothesized that younger adolescents may experience fewer social difficulties than older adolescents.

\section{Method}

\section{Participants}

Participants with a diagnosis of an obstetric brachial plexus injury were included in this study. Participants and their parent(s) were required to be English speaking (because the questionnaires were validated in English) and live in the United States (to decrease cultural effects). Children were excluded from the study if they had a brachial plexus injury that was not caused obstetrically, if they had a significant cognitive impairment or mental retardation that prevented them from completing the questionnaires, and/or if they had a comorbid chronic health condition.

Two cohorts of participants were included in the data analyses. The first cohort $(N=44)$ was recruited from January 2007 through January 2010 via advertisements posted in three venues: (a) the United Brachial Plexus Network (UBPN) website (a national website that provides information and support for families and individuals with brachial plexus injuries); (b) the UBPN bi-annual publication, Outreach; and, (c) in the Rehabilitation Medicine clinics at Children's Mercy Hospital in Kanas City, Missouri and at the Cincinnati Children's Hospital and 
Medical Center in Cincinnati, Ohio. All the advertisements instructed participants to contact the study coordinator to receive more information about the study, as well as the study packets if they wished to participate.

The second cohort $(N=40)$ was recruited from November 2011 through September 2012. These participants were directly recruited during their appointments in the Rehabilitation Medicine Clinics at Children's Mercy Hospital in Kansas City, Missouri and Cincinnati Children's Hospital and Medical Center in Cincinnati, Ohio. Four families from the second cohort refused to participate in this study at the Cincinnati Children's Hospital and Medical Center. One refused due to time constraints and three were not interested.

Independent samples $t$-tests confirmed that there were no significant differences in demographic factors, injury severity factors, or outcome variables between the two cohorts. However, there were significant differences for perceived social support from close friends and frequency of positive coping strategies between the two cohorts, in that the first cohort had significantly higher scores on the perceived social support from close friends and had more frequent use of positive coping strategies compared to the second cohort. The current sample thus consisted of 84 children between the ages of 11 and 17 years $(M=12.81, S D=1.75)$. Thirty-three (39.3\%) of the participants were male and 51 (60.7\%) were female. The majority of youth were Caucasian (64.3\%) followed by African American (15.5\%), Hispanic-American (8.3\%), and Asian-American (2.4\%). A little more than half of the families (54.8\%) were intact (i.e., both biological parents were married and living in the home) while $21.4 \%$ of the families were single-parent households. The family annual income of participants ranged from less than $\$ 10,000$ to $\$ 70,000$ or more, with the majority of participants reporting that they earned $\$ 70,000$ or more $(39.3 \%)$. Approximately $83.3 \%$ of participants reported that they had private insurance, 
$15.5 \%$ reported that they had Medicaid, and $1.2 \%$ reported that their child was not insured. The majority of parents (64.3\% of mothers; $47.6 \%$ of fathers) reported either attending some college/vocational training or having graduated from a four year college.

The majority of youth in this sample reportedly had multiple surgeries for their injuries (39.3\%). The portions of the youth's arm which were affected by their injuries ranged from just their shoulder (11.9\%), elbow (including shoulder, 15.5\%), wrist (including elbow and shoulder, 19.0\%), and hand (including wrist, elbow, and shoulder, 53.6\%). Approximately $82 \%$ of youth reported that their injured arm was shorter than their non-injured arm, while $68 \%$ reported that their shoulder blade stuck out (i.e., "winging").

\section{Measures}

Two study packets were used in this study, one for the child and one for the parent. The parent packet included the Family Information Form, Living with a Chronic Impairment-Parent Version, and the Brachial Plexus Social Questionnaire-Parent Report. The youth packet included Living with a Chronic Impairment-Youth Version, Piers-Harris Self-Concept Form-2 ${ }^{\text {nd }}$ Edition, KIDCope, Social Support Scale for Children, and the Brachial Plexus Social QuestionnaireYouth Report.

Family Information Form (FIF, Appendix A). The FIF was created specifically for the purpose of this study and included family demographic (e.g., parents' education level, family annual income, children's insurance providers) and child's medical information (e.g., areas of the child's arm affected by the injury; number of surgeries the child has had for OBPI). The medical information was used to categorize the clinical severity of the OBPI, based on the total number of regions of the arm that were affected by the injury: category $1=$ shoulder impairments; category 2 = category 1 plus elbow impairment; category 3 = category 2 plus wrist impairment; 
category 4 = category 3 plus hand impairment. For data analyses, injury severity was further classified into "low" (i.e., categories 1 and 2) and "high" (i.e., categories 3 and 4).

\section{Living with a Chronic Impairment-Parent and Youth Versions (LCI-P, LCI-Y,}

Appendices B \& C; Adams, Streisand, Zawacki, \& Joseph, 2002). This questionnaire was an adapted version of the Living with a Chronic Illness measure. The original questionnaire was designed to assess children's health-related social functioning and contained 29 items on both the parent and youth versions. The current questionnaire was adapted for the purposes of this study by changing the wording of the statements to reflect limb impairments rather than chronic illnesses. The statements included on this questionnaire revolved around physical activities (exercising, playing outdoors, etc.), social activities (clubs, friendships, etc.), school issues (involvement in school activities, relationships with classmates and teachers, teasing, etc.), and family relationships. Examples of questions asked on the youth version are, "Other kids tease me about the way I look," "I do not play team sports," and "Teachers treat me different from my classmates." Responses were first made on a dichotomous true/false response scale in relation to whether the statement was "true" or "false" for the respondent. If participants selected "true" in response to the statement, they then were asked whether the problem was due to their injury ("yes/no") and were instructed to rate how much the problem upset them on a 4-point Likert-type scale (not at all, just a little, pretty much, very much).

Two summary scores were calculated (injury-related social difficulties; non-injuryrelated social difficulties). For the purposes of the current study, only the injury-related social difficulties summary score was utilized. To calculate this summary score, item scores were summed from the Likert-type response options for items endorsed as both "true" and "yes." 
Higher scores in the injury-related social difficulties summary score indicated more injuryrelated social difficulties endorsed by children and parents.

The original questionnaire was validated on a sample of chronically ill youth who were between the ages of 8 and 18 years old and was shown to have good psychometric properties (Adams et al., 2002). Internal consistency (alpha) of the original questionnaire was found to be .86 for the parent version and .82 for the youth version. Validity was established via correlation of LCI scores to scores on related measures (e.g., Child Behavior Checklist; Achenbach, 1991). Additionally, significant correlations were found between comparable summary scores on the LCI-Y and LCI-P; minimal correlations were found between illness-related and non-illnessrelated scores, indicating a distinction between the two scores calculated on this questionnaire (Adams et al., 2002).

In another study, the LCI was adapted for use with a sample of youth with burn injuries (Piazza-Waggoner, Butcher, Adams, Goldfarb, \& Slater, 2004). Results from this study indicated that the scores from both versions of the LCI were significantly correlated with various medical variables (e.g., age at time of injury, number of days spent in the hospital, total burn surface area). Also, both parent and youth versions of the LCI were significantly correlated with each other. These results provide further evidence of the validity of the LCI measure, even when the measure is adapted for use with a different population.

\section{Piers-Harris Self-Concept Form-2 ${ }^{\text {nd }}$ Edition (PH-2; Piers, Harris, \& Herzberg,}

2002). The PH-2 was used to assess the self-concept of youth between the ages of 7 to 18 years old. The questionnaire included 60 items that cover six subscales: physical appearance and attributes; intellectual and school status; happiness and satisfaction; freedom from anxiety; behavioral adjustment; and popularity. Also included in this questionnaire are two validity scales 
that can identify biased responding. The items on the questionnaire are descriptive statements and children are asked to determine if the item applies to them by selecting a "yes" or "no" response. The "yes" or "no" responses are assigned a value of either " 0 " or " 1 " depending on the specific item. In addition to a total score, which measures global self-concept, each subscale receives a separate standardized score. Higher scores on the PH-2 indicate higher ratings of selfconcept. For the purposes of the present study, only the total score was utilized as a measure of global self-concept, as it is the most reliable measure on the $\mathrm{PH}-2$ and it has the most research support (Piers, Harris, \& Herzberg, 2002).

The PH-2 was re-standardized using a normative sample of 1,387 children and adolescents (ages 7 to 18 years; 689 males) and has demonstrated good reliability and validity for its scores. Internal consistency (alpha) of the total score for the entire standardization sample was found to be .91 . In addition, the PH-2 demonstrated adequate convergent validity with similar measures (e.g., My Worst Experience Scale; Piers, Harris, \& Herzberg, 2002).

KIDCope (Spirito, Stark, \& Williams, 1988). The KIDCope is a ten item questionnaire that assesses youth's use of coping strategies. The questionnaire has two versions, one for younger children (ages 7-12) and one for older children (ages 13-18); however, only the version for older children was used in this study. To facilitate participants' responding about the use of coping strategies related to their OBPI, a cover page was used that asked participants to describe a problem that was related to their OBPI and which occurred in the past month. After they described the problem, participants were then asked to answer three questions regarding the problem they just described. The questions asked if the situation made them nervous, if the situation made them sad, and if the situation made them angry or mad. Participants ranked their responses on a 5-point scale, with 0 corresponding to "not at all" and 4 corresponding to "very 
much.” The results from this portion of the KIDCope were not utilized in the current study; however, these data provided qualitative information on some of the specific problems youth with OBPI experience.

After completing the cover page, participants were asked to think of the problem they just described when answering the next ten questions. Each question represented a different coping strategy, including positive/approach-style coping strategies (cognitive restructuring, problem solving, social support, and emotional regulation) and negative/avoidant-style coping strategies (distraction, social withdrawal, blaming others, self-criticism, wishful thinking, and resignation). An example of a positive/approach-style coping item is "I thought of ways to solve the problem" while an example of a negative/avoidant-style coping item is "I realized I brought the problem on myself and blamed myself for causing it." Youth were instructed to answer each item in relation to the frequency (4-point scale; "not at all" to "almost all the time") they used the specified coping strategy and its effectiveness (5-point scale; "not at all" to "very much"). To score the KIDCope, scores from both the frequency and effectiveness ratings are summed, with higher scores indicating higher levels of frequency and more effectiveness. For the purposes of the current study, only the frequency of positive/approach-style coping strategies was used, as these strategies are considered to be important resistance factors that may be associated with lower social difficulties or higher self-concept.

The psychometrics of the KIDCope are acceptable (Spirito, et al., 1988), with test-retest correlations ranging from .41 to .83 across the ten items in the frequency domain. Validity was examined by comparing the KIDCope to the Coping Strategies Inventory, with correlations ranging from .33 to .77 between the two measures (Spirito et al., 1988). 
Social Support Scale for Children (SSSC; Harter, 1985). This scale was used to assess perceived social support that children receive from parents, teachers, classmates, and a close friend. Youth were instructed to read a sentence and then choose one side of the sentence that was most like them. Examples of sentences include, "Some kids have parents who don't really understand them but other kids have parents who do understand them," and "Some kids have classmates who like them the way they are but other kids have classmates who wish they were different." Respondents first chose which sentence is true for them and then they selected one of these two options: "really true for me" or "sort of true for me." Thus, responses were scored on a 4-point scale. Summary scores were calculated for each of the four domains of perceived social support (parents, teachers, classmates, and a close friend). Higher summary scores indicate a higher level of perceived social support from the respective domain. For the purposes of the current study, total scores from each of the four domains of perceived social support were used.

The SSSC has demonstrated adequate psychometric properties and has been used extensively in the pediatric and clinical child literature. The internal consistencies (alphas) of the four subscales range from .72 to .88 (Harter, 1985). The SSSC has also demonstrated adequate correlations with similar measures (e.g., global self-worth), thus supporting the convergent validity of its scores (Harter, 1985).

\section{Brachial Plexus Social Questionnaire-Parent and Youth Versions (BPSQ-P, BPSQ-}

Y, Appendices D \& E). This scale was designed for the purpose of this study to assess specific psychosocial concerns of youth with OBPI. Items were developed by brainstorming with health care professionals working in pediatric rehabilitation medicine (e.g., physiatrists, nurses) the possible concerns that youth with OBPI might face on a daily basis. Examples of statements include: "People stare at me because of my arm," "Kids tease me about the way I look," and "I 
wish my arm was normal." Two parallel versions were created, one for youth (self-report) and one for the parent to report on the youth. Responses were made on a 4-point scale, with " 0 " corresponding to "not at all" and "3" corresponding to "very true." Two items on the scale were reverse worded (and scored) to prevent biased responding. Total scores were computed with higher scores indicating more social problems as a result of the OBPI.

\section{Procedure}

In the data collection period for the first cohort, participants who wished to take part in the study contacted the study coordinators. The participants were then mailed two study packets, in separate envelopes, along with a self-addressed stamped envelope for families to return their completed questionnaire packets. Each study packet included a cover letter explaining the purpose of the study and provided contact information if the participants had any questions. At least one parent was required to fill out the parent forms; however, both parents were allowed to complete the questionnaires together if they wanted to do so. Youth were instructed to complete their questionnaires independently but were advised to consult with parents if they needed help understanding any language or instructions. Youth also sealed their completed questionnaires in an envelope before giving them to their parent to mail. No personally identifying information was collected from the participants. The completed packets were mailed back to the study coordinator at Children's Mercy Hospital.

During the data collection period for the second cohort, participants meeting the inclusion criteria were approached by members of the research teams at Children's Mercy Hospital and at Cincinnati Children's Hospital Medical Center during regularly scheduled Rehabilitation Medicine clinic visits. These research members also were members of the rehabilitative multidisciplinary healthcare teams (i.e., clinic or outcome coordinators) at their respective hospitals; 
two members who approached potential participants were certified occupational therapists and another member had a master's degree in public health. All research team members had completed appropriate IRB training (e.g., Collaborative Institutional Training Initiative). A description of the study was given to participants and their parents. Once assent and consent were obtained from the participants and their parents, respectively, directions about how to fill out the study packets correctly were given. Youth were instructed to fill out their forms independently but they were able to pose questions to the research team members if some parts of the questionnaires were unclear. Research team members vacated the room when participants were completing their questionnaires and whenever possible, youth completed the forms in a separate room from their parent(s).

The measures were presented in a predetermined order for all participants. The parent packets took approximately 15-20 minutes to complete, while the youth packets took approximately 40-60 minutes to complete. Participants were allowed to skip any questions that they do not wish to answer. Once the study packets were completed, research team members briefly checked the forms to make sure all pages and questions were filled out correctly and completely. Phone numbers of the families that participated were collected in case it was later discovered that the questionnaires were not completed correctly or completely; if necessary, families were contacted within two weeks to obtain complete information over the telephone. For their participation, youth were provided with a $\$ 10$ gift card and their parent(s) also were provided with a $\$ 10$ gift card. A participant logbook was maintained by both study sites. This logbook contained the phone numbers of each participant as well as a list of participants who refused to participant and their reasons for refusing participation. 


\section{Results}

An a priori power analysis was calculated using an effect size of 0.35 and six predictors (four domains of perceived social support, coping strategies frequency, and limb severity) in a multiple regression analysis. The total sample size needed to have a power level of 0.95 was 67 .

\section{Data Management}

Prior to data analysis, all data were checked for issues with missing values, violations of normality and homogeneity, and possible outliers. Square root (LCI-P, LCI-Y, SSSC-Teacher, and SSSC-Close Friend domains, BPSQ-P, BPSQ-Y) and log (SSSC-Parent domain) transformations were computed for total scores which violated normality. Scores from one participant were found to be an outlier and therefore data from this participant were excluded for all analyses. Multicollinearity was also explored prior and subsequent to conducting data analyses. Subscales from the SSSC were found to be significantly correlated; however, none of these correlations exceeded .60 , which would indicate potential concerns with multicollinearity. Also, subsequent VIF and Tolerance values examined after data analyses did not indicate any serious concerns with multicollinearity.

Problems with missing data were prevalent in the current study sample, most often due to participants incorrectly completing study measures. In instances when participants were missing fewer than $10 \%$ of the total items from one measure, item-mean imputation was used. This approach was used for six participants on the SSSC measure. In addition, ten participants were missing items on the PH-2. According to the PH-2 manual (Piers, Harris, \& Herzberg, 2002), items with missing scores should be scored as zero; thus, this approach was utilized for the ten participants with these missing scores. In all, there were 29 participants who were missing one or more study measures, thus the overall sample size was compromised in the data analyses. 
Independent samples $t$-tests confirmed that there were no significant differences on demographic, injury severity factors, or independent/outcome variables between participants with missing data and participants without missing data.

Due to the limited sample size as a result of missing data, a post-hoc power analysis was calculated using a lower effect size. With an effect size of .25 , a $p$ value of .05 , six predictors (four domains of social support, frequency of positive coping strategies, and limb severity), and a sample size of 57 (i.e., 57 was the smallest sample size used in analyses), the power level equaled .76. Using the same dimensions (i.e., effect size of $.25, p$ value $.05, N=57$ ) but with eight predictors (accounting for the age/gender and interaction predictors included in the moderation analyses), the power level was .69. These results suggest that the current study was somewhat underpowered statistically.

\section{Statistical Analyses to Address Study Aims}

Means and standard deviations were computed for all measures of psychosocial functioning and were compared to published means from studies using the same measures with samples of youth with various other health conditions (e.g., burn injuries, chronic illnesses). Bivariate correlations were calculated between all study variables. Multiple regression analyses were conducted using frequency of positive coping strategies (KIDCope), four domains of perceived social support (SSSC), and injury severity as predictors. Total parent- and youthreported social functioning scores (LCI-P, LCI-Y) and total self-concept scores from the PH-2 were used as outcome measures. In addition, age and gender were examined as potential moderators in each of the regression analyses. The psychometric properties of both versions of the BPISS were explored; specifically, Cronbach's Alpha and item-to-total correlations were used to assess reliability, while bivariate correlations with the LCI served as a measure of 
concurrent validity. Finally, an exploratory multiple regression analysis was conducted using scores from the BPSQ-P and BPSQ-Y as outcome measures, respectively with frequency of positive coping strategies (KIDCope), perceived social support from four domains (SSSC), injury severity, and age as predictors.

\section{Results for Study Aims}

Bivariate associations among all study variables are presented in Table 1.

Aim 1. Means and standard deviations from the LCI, SSSC, KIDCope, and the PH-2 are presented in Table 2. On average, youth and parents reported few injury-related social difficulties, and youth reported high levels of perceived social support across all four domains as well as moderate use of positive coping strategies. In addition, youth in this sample reported selfconcept scores within the normal limits compared to the PH-2 standardization sample.

Informal contrasts were used to compare scores for the current sample of youth with OBPI to those published in the literature for youth with other injuries and/or illnesses. Compared to a sample of youth with various chronic illnesses (e.g., asthma, cancer; Adams et al., 2002), the sample tended to report fewer social difficulties, on average, related to their health condition (i.e., injury-related score on the LCI). In contrast, compared to a group of youth with burn injuries (Piazza-Waggoner et al., 2004), youth with OBPI tended to report more injury-related social difficulties on average (see Table 3). In comparison to youth with burn injuries (Girolami, 2005), youth in the current study tended to report, on average, higher levels of perceived social support across all four domains of the SSSC (Table 4). Furthermore, the participants in this study had similar levels of perceived social support compared to youth with congenital limb deficiencies (Varni et al., 1992; Table 5). Due to differences in scoring of the KIDCope (e.g., 
some studies utilized different items when calculating total coping scores), means and standard deviations from other samples of youth could not be used as comparisons to current results.

Aim 2. Two multiple regression analyses were conducted using scores from the KIDCope, the four domains of the SSSC, and injury severity as the predictor variables and injury-related scores from the LCI-P and the LCI-Y as the outcome variables. The combined variables did not significantly predict parent-reported scores of youth social functioning, $F(6,50)$ $=1.79, p=.12, N=57$. For youth report of social functioning, the same combined variables were approaching significance, $F(6,53)=2.23, p=.05, N=60$. The amount of variance accounted by this model was relatively small (Adj. $\left.R^{2}=.11\right)$ and no individual predictors were significant in this model.

To examine the possible moderating effects of gender on the relation between frequency of positive coping strategies and social functioning, a full model of predictors (i.e., four domains of perceived social support, injury severity, frequency of positive coping strategies, and gender) was entered as the first step of the model with the interaction of gender and positive coping strategies entered as the second step of the model. No significant models emerged for the parent report of youth social functioning; step $1-F(7,49)=1.70, p=.13$; step $2-F(8,48)=1.57, p=$ $.16, N=57$. Similarly, no significant models were found for youth report of social functioning; step $1-F(7,52)=2.09, p=.06$; step $2-F(8,51)=1.83, p=.09, N=60$. These results suggest that gender was not a significant moderator of the relation between coping strategies and social functioning in this sample of youth.

Additional analyses were conducted in order to determine the possible moderating effects of age on the relation of perceived social support from parents and classmates with youth social functioning. Two models each were used to investigate the perceived social support from parents 
and classmates, respectively. Both models included seven predictors (i.e., four domains of perceived social support, injury severity, frequency of positive coping strategies, and age) entered as the first step of the model and an eighth predictor (interaction of age and perceived social support from parents or classmates) entered as the second step of the model. Given the restricted sample size, there may have been some potential concerns with running these models with eight predictors; nonetheless, it was decided to maintain the same models. Parent and youth report of social functioning each were used as outcomes; therefore a total of four additional models were run.

For the parent report of social difficulties, no significant models emerged for either the youth-report of perceived social support from parents (step $1-F(7,49)=1.60, p=.16$; step 2 $F(8,48)=1.41, p=.22, N=57)$ or the youth-report of perceived social support from classmates $($ step $1-F(7,49)=1.60, p=.16 ;$ step $2-F(8,48)=1.38, p=.23, N=57)$.

For the youth report of social difficulties, the model including age and social support from classmates was not significant, step $1-F(7,52)=2.23, p=.05$; step $2-F(8,51)=2.05, p=$ $.06, N=60$. The other model that included age and social support from parents for the youth report of social difficulties was significant, step $1-F(7,52)=2.23, p=.05$; step $2-F(8,51)=$ $2.59, p=.02, N=60$. The variance accounted for step 1 of the model was $23.1 \%\left(\right.$ Adj. $R^{2}=.13$ ) while the variance accounted for in step 2 of the model was $28.9 \%$ (Adj. $R^{2}=.18$ ). None of the individual predictors were significantly associated with youth-reported social difficulties in step 1. The standardized coefficients and significance level for the variables included in step 2 of the model are presented in Table 6 . As evidenced by these values, the interaction between perceived social support from parents and youth age was significant $(\beta=.26, p=.05)$. To interpret this interaction, simple slopes were calculated using the Interaction Program (Soper, 2011). 
However, further examination of the simple slopes revealed that the association between youthreported social support from parents and age were not significantly different from zero. Figure 1 provides a demonstration of the potential interaction.

Aim 3. A multiple regression analysis was conducted using a full model of predictors (scores from the KIDCope, the four domains of the SSSC, and injury severity) and the total selfconcept scores from the PH-2 as the outcome variable. Results indicated that these combined predictors were significantly associated with total self-concept scores, $F(6,51)=3.96, p<.01, N$ $=58$ and accounted for $31.8 \%$ of the variance $\left(\operatorname{Adj} . R^{2}=.24\right)$. In review of individual predictors, it was found that the classmate domain from the SSSC was significantly associated with total self-concept scores, $\beta=.54, p<.01$, indicating that increases in perceived social support from classmates tended to be associated with increases in self-concept scores.

To explore the possible moderating effects of gender on the relation between frequency of positive coping strategies and self-concept, a full model of predictors (i.e., four domains of perceived social support, injury severity, frequency of positive coping strategies, and gender) was entered as the first step of the model with the interaction of gender and positive coping strategies entered as the second step of the model. Results indicated a significant model, step 1 $F(7,50)=3.78, p<.01 ;$ step $2-F(8,49)=3.28, p<.01, N=58$. Step 1 of the model accounted for $34.6 \%$ of the variance (Adj. $R^{2}=.26$ ) and step 2 of the model accounted for $34.9 \%$ of the variance (Adj. $\left.R^{2}=.24\right)$. However, the only significant predictor was perceived social support from classmates $(\beta=.53, p<.01)$ and the interaction between frequency of positive coping strategies and gender was not significant $(\beta=-.16, p=.67)$.

Similar to Aim 2, further analyses were conducted to determine the possible moderating effects of age on the relation between perceived social support from parents and classmates and 
self-concept. Two models each were used to examine the perceived social support from parents and classmates, respectively. Both models included seven predictors (i.e., four domains of perceived social support, injury severity, frequency of positive coping strategies, and age) entered as the first step of the model and an eighth predictor (interaction of age and perceived social support from parents/classmates) entered as the second step of the model. Note again that there might have been some statistical power concerns with the limited sample size. For the model including social support from classmates, results suggested a significant model, step 1 $F(7,50)=3.36, p<.01 ;$ step $2-F(8,49)=2.90, p=.01, N=58$. The variance accounted for step 1 of the model was $31.8 \%$ (Adj. $R^{2}=.22$ ), while the variance accounted for in step 2 of the model was $32.1 \%$ (Adj. $R^{2}=.21$ ). However, there was only a main effect for perceived social support from classmates $(\beta=.53, p<.01)$ and the interaction between social support from classmates and age was not significant $(\beta=.06, p=.64)$.

Finally, for the model including social support from parents, results indicated a significant model, step $1-F(7,50)=3.34, p<.01 ;$ step $2-F(8,49)=2.86, p=.01, N=58$. The variance accounted for step 1 of the model was $31.8 \%\left(\right.$ Adj. $R^{2}=.22$ ) while the variance accounted for in step 2 of the model was $31.8 \%$ (Adj. $R^{2}=.21$ ). However, like the previous model, the only significant predictor was perceived social support from classmates $(\beta=.54, p<$ $.01)$. There was no main effect for perceived social support from parents $(\beta=.54, p<.01)$ and the interaction between social support from parents and age was not significant $(\beta=.01, p=.94)$.

Aim 4. The ten-item BPSQ-P and BPSQ-Y both were found to have satisfactory levels of internal consistency as assessed by Cronbach's alpha $(0.74,0.74$, respectively). The item-to-total correlations for both measures are presented in Tables 7 and 8. Based on these correlations, it appears that the majority of items had moderate correlations with the overall total score, with the 
exception of Item 5. Because of this, Item 5 was dropped from the scale. Cronbach's alpha was then re-calculated and the resulting Cronbach's alpha for the BPSQ-P was .75 and .77 for the BPSQ-Y. The nine-item scale (i.e., with Item 5 deleted) was used in the following analyses.

The BPSQ-P was found to correlate significantly with the LCI-P $(r=.71, p<.01)$ and the BPSQ-Y was found to correlate significantly with the LCI-Y $(r=.62, p<.01)$, indicating that the BPSQ appears to be an appropriate assessment of social functioning specifically in youth with OBPI.

Aim 5. A multiple regression analysis was conducted using a full model of predictors (scores from the KIDCope and the four domains of the SSSC, injury severity, and age) with the total OBPI-related social difficulties scores from the nine-item BPSQ-P and the BPSQ-Y, respectively. The combined predictors were not significantly associated with parent report of social difficulties, $F(7,51)=1.50, p=.19, N=59$. However, the combined predictors were significantly associated with youth report of social difficulties, $F(7,53)=3.47, p<.01, N=61$. This model accounted for $31.5 \%$ of the variance (Adj. $\left.R^{2}=.22\right)$. Perceived social support from classmates $(\beta=-.33, p<.05)$ was found to be significant individual predictor of youth-reported social difficulties, while age was approaching significance $(\beta=.22, p=.07)$. These results suggest that increases in perceived levels of social support from classmates were associated with fewer youth-reported social difficulties.

\section{Discussion}

Children with OBPI may be at risk for social functioning difficulties due to the visible nature and physical limitations often associated with their injuries. However, only one study has explored the psychosocial adjustment of youth with these injuries, and this study was limited to a Swedish population. The current study sought to address the relative lack of psychosocial 
research conducted with youth with OBPI in the United States. In addition to providing descriptive data on measures of psychosocial functioning, the current study investigated specific predictors believed to be associated with injury-related social functioning and overall selfconcept in these youth. Furthermore, initial psychometric properties of a brief scale of social difficulties specific to youth with OBPI were examined.

Means and standard deviations from the measures completed by participants in this study indicated that youth with OBPI seemed to report more injury-related social difficulties than youth with burn injuries (Piazza-Waggoner et al., 2004), but less than youth with chronic illnesses (Adams et al., 2002). Although this was an informal comparison of means between samples, it may be that youth with OBPI report fewer social difficulties than youth with chronic illnesses because youth with chronic illnesses may have complex treatment regimens (e.g., medications, dietary restrictions) that impact their overall social activities and functioning more so than youth with OBPI. In contrast, because burn injuries can involve various parts of the body, while OBPI involves some aspect of the upper limb, pediatric burn patients may not experience as much disruption in their social activities or functioning as a result of their injury.

Additionally, youth in this sample reported relatively higher levels of perceived social support than youth with burn injuries (Girolami, 2005). Although OBPI and burn injuries are similar in terms of visibility of the injury and possible mobility impairments, the difference in perceived social support may be due to the chronic nature of OBPI compared to the acute onset of burn injuries. It could be that because youth with OBPI have grown up with their injuries, their social support systems are relatively intact; whereas, youth who sustain burn injuries may experience fluctuations in their social support systems. In addition, the sample of youth included in the Girolami (2005) study were burned relatively close to their participation in the study, and 
so it may be that time of assessment and the acute aspect of their condition was responsible for the differences in means of perceived social support between these two samples. On the other hand, when compared to a sample of youth with congenital limb deficiencies (Varni et al., 1992), youth with OBPI appeared to have comparable levels of perceived social support. This is not surprising, given the similar symptom onset and presentation shared by OBPI and congenital limb deficiencies.

Standardized scores from the PH-2 revealed that the majority of participants in this study had average ratings (i.e., within the normal limits) of global self-concept compared to the standardization sample, indicating that the majority (52.5\%) of this sample was not experiencing any clinically significant concerns in terms of their self-concept. It appears that the participants in this study, in general, likely are capable of understanding their strengths and weaknesses in various domains of functioning and have a balanced view of their self-concept. Only two participants $(2.5 \%)$ endorsed scores that would place them in the low range of self-concept, suggesting that these participants had concerns or doubts about their self-concept and competencies in various areas. Approximately $43.7 \%$ of participants endorsed high ratings on the PH-2, indicating very positive self-concept and high confidence in a variety of domains. However, the average to high self-concept scores of youth in this sample are not consistent with previous findings that suggested that youth with physical disorders experience decreases in their self-concept compared to healthy controls (Lavigne \& Faier-Routman, 1992). In addition, Strombeck and Fernell (2003) found that youth with OBPI had lower self-esteem compared to youth without OBPI. The discrepancy between previous and current findings may be due to the use of different measures and constructs to assess self-concept. Additionally, youth in this sample appeared to be functioning well (as evidenced by their scores on measures included in 
this study) and it may be that our sampling procedure (e.g., a portion of participants were selfselected) did not capture youth who were experiencing self-concept concerns.

The results from the regression analyses that utilized youth- and parent-reported social functioning as outcome variables indicated that a full model of variables (i.e., frequency of positive coping strategies, perceived social support across four domains, and injury severity) was not significant in predicting scores. This finding was unexpected given previous research that suggests that youth with physical disorders experience behavioral difficulties (e.g., Lavigne \& Faier-Routman, 1992). However, this study employed different outcomes measures than previous studies (e.g., Lavigne \& Faier-Routman, 1992) and it could be that the outcomes used in the current study were not able to capture any concerns. It also could be that other predictors (e.g., SES, age) may be better able to explain differences in social functioning in youth with OBPI. Furthermore, with the exception of the frequency of positive coping strategies and injury severity, the lack of findings may be due to the study being underpowered, given that the majority of perceived social support domains were significantly and moderately correlated with youth- and parent-reported social functioning.

Previous research suggested that age (Berndt, 1979; Bokhorst, et al., 2010) and gender (Lynch et al., 2007) might moderate the association among some of the variables included in the social functioning analyses. For the parent report of social functioning, age and gender were not significant moderators of the relation between frequency of positive coping strategies and social support from parents and classmates, respectively. In the regression model examining youthreported social functioning, the interaction between age and perceived social support from parents was significant in the regression model; however, further examination of the simple slopes revealed that this association was not statistically significant from zero. Furthermore, age 
and gender most likely are not significant moderators in the current study, given that these variables generally had low correlations with the study variables included in the moderation analyses.

In addition, the current study examined the same variables (i.e., four domains of social support, frequency of positive coping strategies, and injury severity) and their association with global self-concept. The results from these analyses indicated that a full model of predictors significantly accounted for total self-concept, although the amount of variance was somewhat small. In particular, it was found that perceived support from classmates was associated with increases in total self-concept. This finding is consistent with results from the study conducted by Varni and colleagues (1992) with a sample of youth with congenital limb deficiencies. Furthermore, these results are consistent with research that suggests social support is related to overall adjustment (Jemta et al., 2009). Although peer support generally matters for all adolescents (e.g., Berndt, 1979; Bokhorst et al., 2010), it seems that social support from classmates plays a particularly important role in the self-concept of youth with OBPI. It may be that youth with OBPI who sense that their classmates support them in turn leads to these youth feeling accepted and included, despite having a notable injury. On the other hand, adolescents with OBPI who do not perceive high levels of social support from their classmates may feel isolated and excluded and as such, feel less competent in their abilities, resulting in lower selfconcept scores. For example, an adolescent with OBPI may have a functional impairment that limits his/her participation in sports, which in turn can lead to this adolescent being excluded from peer groups or being selected last in Physical Education activities. Being excluded or selected last in sporting activities may lead the adolescent to develop a negative self-concept. However, future research would need to verify that peer support is particularly relevant for youth 
with OBPI by contrasting results with a healthy control group. Further analyses also revealed that age and gender were not significant moderators in this relation, despite previous research suggesting that age and gender might moderate the relation between social support from parents and classmates and coping strategies, respectively (Berndt, 1979; Bokhorst, et al., 2010; Lynch et al., 2007).

Consistent with previous research (Lavigne \& Faier-Routman, 1992; 1993; Varni et al., 1992; Jemta et al., 2009; Antle, 2004; Browne et al., 1985), injury severity was not found to be a significant predictor of social functioning or total self-concept. In addition, injury severity was not significantly correlated with any of the study variables, suggesting that injury severity was not contributing substantially to the overall models examined in this study. Still, it will be important for future research to investigate other potential predictors of psychosocial outcomes in youth with OBPI, particularly given the relative dearth of such research published on this patient population. For example, studies with youth with spina bifida suggest that SES might be associated with psychosocial problems and the use of various coping strategies (Barakat \& Linney, 1995; Devine, Holbein, Psihogios, Amaro, \& Holmbeck, 2012); therefore these variables may have relevance to youth with OBPI. Furthermore, frequency of positive coping strategies was not a consistent predictor of social functioning or self-concept in this sample, despite research suggesting that coping strategies are related to psychosocial functioning (Lavigne \& Faier-Routman, 1993). Although some studies suggested effectiveness of coping strategies may be more important to examine (Jemta et al., 2007), it was assumed that youth would more frequently use those coping strategies which they believed to be effective (Spirito et al., 1988); thus, our use of frequency scores should have encompassed some aspect of efficacy. However, the lack of significant findings with frequency of positive coping strategies does not appear to be 
due to the current study being underpowered, given that this variable had low correlations with other study variables. As such, it may appropriate for future studies to explore further other aspects of coping (e.g., effectiveness of coping strategies, frequency of negative coping strategies).

Due to the fast-paced nature of most pediatric clinics, it is important to develop brief but effective screening measures for psychosocial concerns in youth. Given that medical team members note social concerns in youth with OBPI, we developed a screening questionnaire (BPSQ) for these youth and their parents each to complete. The initial psychometric properties of the BPSQ seem promising. This scale demonstrated adequate internal consistency and moderate correlations with the LCI, a longer measure of social functioning in youth with chronic illness or injury, thereby supporting the concurrent validity of the BPSQ scores. In addition, the item-tototal correlations were all moderate in size, with the exception of one item. This item (i.e., "My child is okay with being in public places, like shopping, going to the movies, or out to eat") may have been worded too vaguely on both forms of the BPSQ, even though the concept fundamentally seemed important in the initial construction of the measure. Although the psychometric properties of the BPSQ will need to be examined further, the scale might prove to be an appropriate screener of social difficulties specific to youth with OBPI Rehabilitation Medicine clinics.

Finally, the exploratory analyses which analyzed the parent- and youth-reported social difficulties using the BPSQ demonstrated a significant relation between youth-reported social difficulties and a full model of predictors. In particular, perceived social support from classmates emerged as a significant predictor of youth-reported social difficulties specific to OBPI. The 
significance of perceived social support from classmates again is consistent with previous research in youth with congenital limb deficiencies (Varni et al., 1992).

Results from the current study suggest certain psychosocial variables, in particular perceived social support from classmates, may be associated with social functioning and selfconcept in youth with OBPI. This study suggests that it may be appropriate for clinicians to examine the peer relationships of youth with OBPI in order to monitor their psychosocial functioning. Furthermore, clinicians should address possible peer difficulties (e.g., by teaching positive social skills or social problem solving) in youth with OBPI in order to prevent any declines in self-concept. It also may be important to determine whether educational programs regarding OBPI in children's classes might be effective in reducing social concerns, much like school visits used with pediatric burn patients (e.g., Blakeney et al., 1995). As children spend the majority of their days in school, this environment may be important to target in order to promote positive social skills in children with OBPI.

This study has several limitations. First, with a relatively small sample size, the study may have had been underpowered and thus the ability to detect statistically significant findings may have been limited. In addition, the amount of missing data in this study further limited our sample size and subsequent power level. In fact, the lack of significant findings using youth-and parent-reported social functioning as outcome variables may be due to a lack of power. However, power does not appear to be a concern with the lack of significant findings with age, gender, frequency of positive coping strategies, and injury severity, given that these variables had low correlations with other study variables. Another limitation in the study may be its measures. In particular, although some measures were specific to children with chronic injuries (i.e., LCI and BPSQ), remaining measures were not. With the exception of the LCI and the BPSQ (both of 
which were validated with pediatric conditions), the measures included in this study were not specific to chronic injuries. For example, it could be that certain items on these non-specific measures were not relevant to youth with OBPI and as such, may not have been sensitive enough to detect differences with these patients. Similarly, our use of a global self-concept score may not accurately capture specific difficulties that youth with OBPI experience, such as possible deficits related to physical appearance or functioning.

Other limitations of the current study may be due to participant characteristics. First, it is important to note that a portion of the sample was self-selected in that participating families read advertisements and initiated contact with research staff. Consequently, these individuals may have been higher functioning, given that they were in touch with resources (i.e., website and newsletter) that provide guidance and support. It also may be that participants in this sample provided socially desirable responses to the questionnaires or were responding to possible demand characteristics. For example, because some participants completed measures during clinic appointments, families may have mistakenly assumed that their answers would be shared with their medical team. Furthermore, participants recruited in clinic comprised a convenience sample and subsequent selection biases may have accounted for the lack of significant findings. In particular, it may be that these families did not have as many social difficulties as youth who do not attend their regularly scheduled clinic visits. Finally, the cross-sectional design of this study prohibits any causal inferences based on the findings.

Despite these limitations, the current study takes important steps toward understanding better the social functioning of youth with OBPI, a relatively understudied patient population. Future studies should continue with this line of research using larger and more representative samples of patients, psychometrically sound and sensitive measures, and perhaps a longitudinal 
design to detect aspects of functioning that may change across time for these patients. Given that our results suggest more perceived social support from classmates is associated with increased self-concept, future research should continue to investigate this relation as well as explore the influences of classmate support on other outcomes (e.g., behavioral problems, quality of life). Additionally, identifying other variables that are associated with key patient outcomes, such as social functioning and self-concept, may assist clinicians in detecting those individuals in need of additional services (i.e., psychological). Similarly, a better understanding of factors associated with psychosocial functioning in these youth can inform future research in devising effective interventions to promote better adjustment. In fact, research on social skills interventions with other populations of youth with chronic injuries indicates that these interventions are effective at improving social functioning (e.g., Barakat et al., 2003). Findings such as these suggest that more research examining variables associated with social functioning is warranted in order to devise effective interventions to promote positive psychosocial adjustment in children and adolescents with OBPI. 


\section{References}

Achenbach, T.M. \& Edelbrock, C. (1983). Manual for the Child Behavior Checklist and Revised Child Behavior Profile. USA: Queen City Printers Inc.

Achenbach, T. M. (1991). Manual for the Child Behavior Checklist/4-18 and 1991 Profile. Burlington: University of Vermont, Department of Psychiatry.

Adams, C. D., Streisand, R., Zawacki, T., \& Joseph, K. E. (2002). Living With a Chronic Illness: A measure of social functioning in children and adolescents. Journal of Pediatric Psychology, 27, 593-605.

Adler, J.B, Patterson, R.L. (1967). Erb's Palsy: Long-term results of treatment in eighty-eight cases. Journal of Bone and Joint Surgery, 49A(6), 1052-1063.

Antle, B.J. (2004). Factors associated with self-worth in young people with physical disabilities. Health \& Social Work, 29(3), 167-175.

Ayers, T.S., Sandler, I.N., West, S.G., \& Roosa, M.W. (1996). A dispositional and situational assessment of children's coping: Testing alternative models of coping. Journal of Personality, 64, 923-958.

Barakat, L.P., Hetzke, J.D., Foley, B., Carey, M.E., Gyato, K., \& Phillips, P.C. (2003). Evaluation of a social-skills training group intervention with children treated for brain tumors: A pilot study. Journal of Pediatric Psychology, 28(5), 299-307.

Barakat, L.P. \& Linney, J.A. (1995). Optimism, appraisals, and coping in the adjustment of mothers and their children with spina bifida. Journal of Child and Family Studies, 4(3), 303-320.

Barrera, M. (1986). Distinctions between social support concepts, measures, and models. American Journal of Community Psychology, 14(4), 413-445. 
Berndt, T.J. (1979). Developmental changes in conformity to peers and parents. Developmental Psychology, 15(6), 608-616.

Billings, A.G. \& Moos, R.H. (1981). The role of coping responses and social resources in attenuating the stress of life events. Journal of Behavior Medicine, 4, 139.

Blakeney, P., Moore, P., Meyer, W., Bishop, B., Murphy, L., Robson, M., \& Herndon, D. (1995). Efficacy of school reentry programs. Journal of Burn Care and Rehabilitation, $16,466-472$.

Browne, G., Byrne, C., Brown, B., Pennock, M., Streiner, D., Roberts, R., Eyles, P., Truscott, D., \& Dabbs, R. (1985). Psychosocial adjustment of burn survivors. Burns, 12, 28-35.

Bokhorst, C.L., Sumter, S.R., \& Westenberg, P.M. (2010). Social support from parents, friends, classmates, and teachers in children and adolescents aged 9 to 18 years: Who is perceived as most supportive? Social Development, 19(2), 417-426.

Davidson, T.N., Bowden, M.L. \& Feller, I. (1981). Social support and post burn adjustment. Archive of Physical Medicine and Rehabilitation, 62, 274.

Devine, K.A., Holbein, C.E., Psihogios, A.M., Amaro, C.M., \& Holmbeck, G.N. (2012). Individual adjustment, parental functioning, and perceived social support in Hispanic and non-Hispanic white mothers and fathers of children with spina bifida. Journal of Pediatric Psychology, 37(7), 769-778.

Girolami, P. (2005). The impact of a school reentry program on the psychosocial adjustment of children with burn injuries. Dissertation Abstracts International, 65(12-B), 6651.

Harter, S. (1982). The perceived competence scale for children. Child Development, 53, 87-97. Harter, S. (1985). Manual for the Social Support Scale for Children. Denver, CO: University of Denver. 
Harter, S. (1988). The Self-Perception Profile for Adolescents. Denver, CO: University of Denver.

Isberg, E. \& Kjellman, B. (1999). Multidisciplinary assessment of children with deficits relating to attention, motor activity and perception: Evaluation of the ANSER model. Child: Care, Health and Development, 5, 359-376.

Jemta, L., Dahl, M., Fugl-Meyer, K.S., \& Stensman, R. (2005). Well-being among children and adolescents with mobility impairment in relation to demographic data and disability characteristics. Acta Paediatrica, 94, 616-623.

Jemta, L., Dahl, M., Nordahl, G., \& Fugl-Meyer, K.S. (2007). Coping strategies among Swedish children and adolescents with mobility impairment in relation to demographic data, disability characteristics, and well-being. Acta Paediatrica, 96, 1184-1189.

Jemta, L., Fugl-Meyer, K.S., Oberg, K., \& Dahl, M. (2009) Self-esteem in children and adolescents with mobility impairment: Impact on well-being and coping strategies. Acta Paediatrica, 98, 567-572.

Kovacs, M. (1983). The children's depression inventory. Psychopharmacology Bulletin, 21, 995 998.

Lavigne, J.V. \& Faier-Routman, J. (1992). Psychological adjustment to pediatric physical disorders: A meta-analytic review. Journal of Pediatric Psychology, 17(2), 133-157.

Lavigne, J.V. \& Faier-Routman, J. (1993). Correlates of psychological adjustment to pediatric physical disorders: A meta-analytic review and comparison with existing models. Journal of Developmental and Behavioral Pediatrics, 14(2), 117-123.

Lawrence, J.W., Fauerbach, J.A., Heinberg, L.J., Doctor, M., \& Thombs, B.D. (2006). The reliability and validity of the Perceived Stigmatization Questionnaire (PSQ) and the 
Social Comfort Questionnaire (SCQ) among an adult burn survivor sample. Psychological Assessment, 18, 106-111.

Lawrence, J. W., Rosenberg, L.E., \& Fauerbach, J.A. (2007). Comparing the body esteem of pediatric survivors of burn injury with the body esteem of an age-matched comparison group without burns. Rehabilitation Psychology, 52(4), 370-379.

Lynch, A.M., Kashikar-Zuck, S., Goldschneider, K.R., \& Jones, B.A. (2007). Sex and age differences in coping styles among children with chronic pain. Journal of Pain and Symptom Management, 33(2), 208-216.

Mendelson, B.K., Mendelson, M.J., \& White, D.R. (2001). Body-esteem scale for adolescents and adults. Journal of Personality Assessment, 76, 90-106.

Moos, R.H. \& Moos, B. (1974). Family Environment Scale. Palo Alto, CA: Consulting Psychologists Press, Inc.

Morrow, G.P, Chiarello, R.J., \& Derogatis, L. (1978). A new scale for assessing patients' psychosocial adjustment to medical illness. Psychological Medicine, 9, 605.

Ouvinen-Birgerstam, P. (1985). I think I am. The Manual. Stockholm, Sweden.

Piazza-Waggoner, C., Butcher, M., Adams, C.D., Goldfarb, I.W., \& Slater, H. (2004). Assessing the relationship between locus of control and social competence in pediatric burn survivors attending summer camp. Journal of Burn Care \& Rehabilitation, 25(4), 349356.

Piers, E.V. (1984). Piers-Harris Children's Self-Concept Scale: Manual (Rev. Ed.). Los Angeles, CA: Western Psychological Services.

Piers, E.V., Harris, D.B., \& Herzberg, D. S. (2002). Manual for the Piers-Harris Children's SelfConcept Scale, Second Edition. Los Angeles, CA: Western Psychological Services. 
Spielberger, C.D. (1973). State-Trait Anxiety Inventory for Children: Preliminary Manual, Palo Alto, CA: Consulting Psychologists Press.

Spirito, A., Stark, L.J., \& Williams, C. (1988). Development of a brief checklist to assess coping in pediatric patients. Journal of Pediatric Psychology, 13, 555-574.

Soper, D.S. (2011). Interaction! [Computer software]. Retrieved from http://www.danielsoper.com/interaction/default.aspx.

Strombeck, C. \& Fernell, E. (2003). Aspects of Activities and Participation in Daily Life Related to Body Structure and Function in Adolescents with Obstetrical Brachial Plexus Palsy: a Descriptive Follow-up Study. Acta Paediatrica, 92, 740-746.

United Brachial Plexus Network. (2011, February). Retrieved from http://www.ubpn.org/.

Varni, J., Setoguchi, Y., Rappaport, L., \& Talbot, D. (1992). Psychological adjustment and perceived social support in children with congenital/acquired limb deficiencies. Journal of Behavioral Medicine, 15(1), 31-44. doi:10.1007/BF00848376.

Wallander, J.L. \& Varni, J.W. (1992). Adjustment in children with chronic physical disorders: Programmatic research on a disability-stress-coping model. In A.M. La Greca, L.J. Siegel, J.L. Wallander, \& C.E. Walker (Eds.), Stress and coping in child health (pp. 279296). New York, NY: The Guilford Press.

Wallander, J.L. \& Varni, J.W. (1998). Effects of pediatric and chronic physical disorders on child and family adjustment. Journal of Child Psychology and Psychiatry, 39(1), 29-46.

Wallander, J.L., Varni, J.W., Babani, L.V., Banis, H.T., \& Wilcox, K.T. (1989). Family resources as resistance factors for psychological maladjustment in chronically ill and handicapped children. Journal of Pediatric Psychology, 14, 157-173. 
Appendix A

\section{Family Information Form}

Study ID \#:

Today's date:

Child Demographic Information

Child's gender: $\square$ Male $\square$ Female $\quad$ Child's age:

Child's Race (circle): Caucasian African-American Asian-American

Hispanic-American Other:

What state do you live in?

\section{Child Injury Information}

Side Affected by Brachial Plexus Injury: $\quad \square$ Right $\quad \square$ Left

Has your child ever had surgery for his/her brachial plexus injury? (Please check all that apply)

Nerve grafting or neurolysis

Muscle-tendon transfers ('Mod Quad' or similar procedure)

Osteotomy (bone rotation)

Other

What portions of your child's arm are affected by this injury? (Please check all that apply)

Shoulder

Elbow

Wrist

Hand

Is the affected arm shorter than the other arm? $\square$ Yes $\square$ No

Does the shoulder blade on the affected side stick out ("winging")? $\quad \square$ Yes $\quad \square$ No

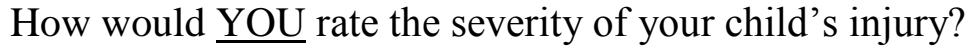

Mild

Moderate

Severe

How does YOUR CHILD rate the severity of his or her injury?

$\square$ Mild

$\checkmark$ Moderate

$\square$ Severe 


\section{Family Demographic Information}

The following family information is asked to provide an overall description of our entire sample:

1. Please make a check in front of each family member that is CURRENTLY living in your child's home.

\begin{tabular}{lll}
$\begin{array}{l}\text { Biological Mother } \\
\text { Adoptive or Step-Mother } \\
\text { Brother (How many? } \\
\text { Grandparent (How many? } \\
\text { Other (list by relationship to child) }\end{array} \quad \begin{array}{l}\text { Biological Father } \\
\text { Adoptive or Step-Father } \\
\text { Sister (How many? }\end{array} \quad$ \\
\hline
\end{tabular}

2. Please make a check in front of your marital status.

Never Been Married / Single

Married to other biological parent

Living with boyfriend / girlfriend deceased)
Divorced / Single

Remarried to step-parent

Widowed (other biological parent is

3. Please check your total, YEARLY family income:

Less than $\$ 10,000$

$\$ 10,000$ - \$19,999

$\$ 20,000-\$ 29,999$

$\$ 30,000-\$ 39,999$

$\$ 40,000$ - $\$ 49,999$

$\$ 50,000-\$ 59,999$

$\$ 60,000$ - $\$ 69,999$

$\$ 70,000$ or more

4. Please check your child's (the patient) INSURANCE:

None/My child is NOT insured

Medicaid

Other (Company Name: 
For the following questions on this page, please list/describe those people (typically, the parents) that PROVIDE FOR THE HOUSEHOLD (help to pay bills, buy food, buy clothes, etc.).

\begin{tabular}{|lll|}
\hline 1 & $=$ & 6th grade or less \\
2 & $=$ & 7th, 8th, or 9th grade \\
3 & $=$ & Some high school (10th or 11th grade) \\
4 & $=$ & Graduate from high school \\
5 & $=$ & Some college (at least 1 year) or specialized training (Vocational) \\
6 & $=$ & Bachelor's degree, graduated from a 4-year college (UF, FSU, USF, etc.) \\
7 & $=$ & Master's degree, doctoral degree
\end{tabular}

5. Using the above scale in the box, please show the highest level of education completed by the people who PROVIDE for the CHILD (help pay bills, buy food, buy clothes). If the person listed is NOT the mother or father of the child, please write who this person is (for example: step-parent, grandparent) next to it.

$\begin{array}{lll}\text { Mother } & = & \\ \text { Father } & = & \end{array}$

6. Please provide a job title \& description for the persons listed in Question \# 24.

Mother (or other):

Father (or other): 


\section{Appendix B (LCI-P)}

\section{INSTRUCTION PAGE}

\section{PARENT FORM}

On the next few pages, you will see a list of items asking about your child's school and social activities.

Read the item. If the statement does NOT describe YOUR CHILD over the PAST 6 MONTHS, then circle "F" for FALSE. After marking "F," do not mark anything else for that item and move to the next question.

HOW UPSET IS YOUR CHILD?

Is it

True or because of Not At Just A Pretty Very

False? Injury? All Little Much Much

\begin{tabular}{|c|c|c|c|}
\hline 1. & My child does not like to eat vegetables. & $\mathrm{T}(\mathrm{F})$ & $\mathrm{Y} \quad \mathrm{N}$ \\
\hline 2. & My child often misses music lessons. & $\mathrm{T}(\mathrm{F})$ & $\mathrm{Y} \quad \mathrm{N}$ \\
\hline
\end{tabular}

If the statement describes your child over the PAST 6 MONTHS and thus is "TRUE," then mark "T" for "TRUE."

After marking "T," move to the next column to the right that asks if the problem is caused by your child's INJURY (Brachial Plexus) or something else (like not having money for it, can't get a ride, etc.). Mark "Y" for "YES" (because of injury) or "N" for "NO" (because of something else).

Then, rate HOW MUCH this problems UPSETS YOUR CHILD by placing an " $X$ " in the column that best describes your child's upset feelings (Not at all, Just a Little, Pretty Much, or Very Much). Please mark "X" in only ONE of the last four boxes for your rating.

HOW UPSET IS YOUR CHILD?

Is it because of

\begin{tabular}{|c|c|c|}
\hline True or & Injury? & Not At \\
\hline
\end{tabular}

\begin{tabular}{|l|l|c|c|c|c|c|}
\hline 1. & My child does not like to play games. & (T) F & ( & & & \\
\hline 2. & My child often misses dentist appointments. & $(\mathrm{T}) \mathrm{F}$ & $\mathrm{Y}(\mathrm{N})$ & $\mathrm{X}$ & & \\
\hline 3. & My child does not like to watch TV. & $\mathrm{T}(\mathrm{F})$ & $\mathrm{Y} \mathrm{N}$ & & & \\
\hline
\end{tabular}

Please call the RESEARCHER if you do NOT understand how to fill out this form. 


\section{LIVING WITH A CHRONIC IMPAIRMENT Parent Report}

Study ID:

Child's AGE:

SEX: $M \quad F$

PARENT: Mother Father

Other:

DIRECTIONS: For each question, show whether your child has had this problem in the past 6 months. If "False", circle "F" under "True or False?" and go to the next question. If "True", circle " $\mathrm{T}$ " and then show whether this problem is caused by your child's injury ( $\mathrm{Y}=\mathrm{Yes} ; \mathrm{N}=\mathrm{No}$ ). Check how much this problem upsets your child by placing an " $\mathrm{X}$ " in the column that best describes your child's feelings (Not at All, Just a Little, Pretty Much, Very Much). Please check only one of the last four boxes per question.

HOW UPSET IS YOUR CHILD?

Is it

True or because of Not At Just A Pretty Very

$\underline{\text { False? Injury? } \quad \underline{\text { All Little }} \underline{\text { Much }} \text { Much }}$

\begin{tabular}{|l|l|c|c|l|l|}
\hline 1. & My child misses school. & T F & Y N & & \\
\hline 2. & $\begin{array}{l}\text { My child does not take part in school activities } \\
\text { (Example: social groups, pep rallies). }\end{array}$ & T F & Y N & & \\
\hline 3. & $\begin{array}{l}\text { My child is left out from activities or games } \\
\text { with other children. }\end{array}$ & T F & Y N & & \\
\hline 4. & $\begin{array}{l}\text { My child does not play team sports (Example: } \\
\text { soccer, football, softball). }\end{array}$ & T F & Y N & & \\
\hline 5. & $\begin{array}{l}\text { My child has problems making or keeping } \\
\text { friends. }\end{array}$ & T F & Y N & & \\
\hline
\end{tabular}

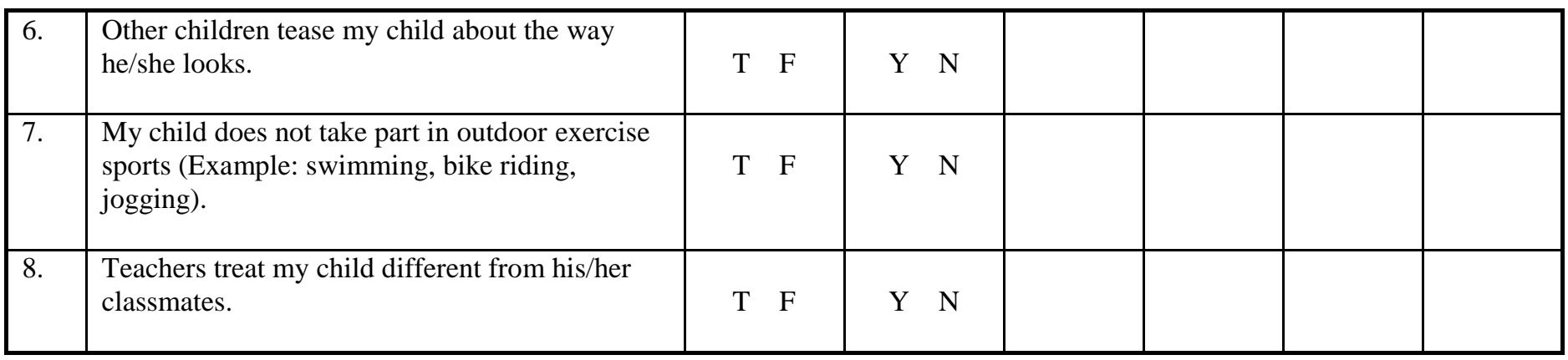


HOW UPSET IS YOUR CHILD?

Is it

True or because of Not At Just A Pretty Very

$\underline{\text { False? }} \underline{\text { Injury? }} \underline{\text { All }} \quad \underline{\text { Little }} \quad \underline{\text { Much }} \quad \underline{\text { Much }}$

\begin{tabular}{|c|c|c|c|c|}
\hline 9. & $\begin{array}{l}\text { My child is not as independent (doing things on } \\
\text { his/her own) as other children his/her age. }\end{array}$ & $\mathrm{T} \quad \mathrm{F}$ & & $\mathrm{N}$ \\
\hline 10. & $\begin{array}{l}\text { My child does not take part in social activities } \\
\text { after school hours (Example: overnight stays, } \\
\text { dances). }\end{array}$ & $\mathrm{T} \quad \mathrm{F}$ & & $\mathrm{N}$ \\
\hline 11. & $\begin{array}{l}\text { My child does not take part in social clubs or } \\
\text { organizations (Example: scouts, youth groups). }\end{array}$ & $\mathrm{T} \quad \mathrm{F}$ & Y & $\mathrm{N}$ \\
\hline 12. & $\begin{array}{l}\text { My child's school grades are below average (D's } \\
\text { and F's). }\end{array}$ & $\mathrm{T}$ & & $\mathrm{N}$ \\
\hline 13. & $\begin{array}{l}\text { My child has problems getting along with people } \\
\text { in our family. }\end{array}$ & $\mathrm{T} \quad \mathrm{F}$ & Y & $\mathrm{N}$ \\
\hline
\end{tabular}

\begin{tabular}{|c|c|c|c|c|c|}
\hline 14. & $\begin{array}{l}\text { My child feels different from other children } \\
\text { his/her age. }\end{array}$ & $\mathrm{TH}$ & Y I & & \\
\hline 15. & $\begin{array}{l}\text { My child feels uncomfortable or uneasy in social } \\
\text { events (Example: parties, get togethers with } \\
\text { family friends). }\end{array}$ & $\mathrm{TH}$ & $\mathrm{Y}$ & $\mathrm{N}$ & \\
\hline 16. & $\begin{array}{l}\text { My child does not like others to know the things } \\
\text { he/she has to do to take care of his/her injury } \\
\text { (physical therapy, medication, etc.). }\end{array}$ & $\mathrm{T}$ & Y & $\mathrm{N}$ & \\
\hline 17. & $\begin{array}{l}\text { My child does not get along with people outside } \\
\text { the family (adults and children). }\end{array}$ & $\mathrm{T}$ & Y & $\mathrm{N}$ & \\
\hline 18. & $\begin{array}{l}\text { My child does not do many activities that his/her } \\
\text { brother(s) \&/or sister(s) do. }\end{array}$ & $\mathrm{T}$ & Y & $\mathrm{N}$ & \\
\hline 19. & My child does not play outside often. & $\mathrm{TH}$ & $\mathrm{Y}$ & $\mathrm{N}$ & \\
\hline 20. & Other children tease my child. & $\mathrm{TH}$ & $\mathrm{Y} \mathrm{I}$ & & \\
\hline
\end{tabular}


HOW UPSET IS YOUR CHILD?

Is it

True or because of Not At Just A Pretty Very

$\underline{\text { False? }}$ Injury? $\quad \underline{\text { All }} \quad \underline{\text { Little }} \quad \underline{\text { Much }} \quad \underline{\text { Much }}$

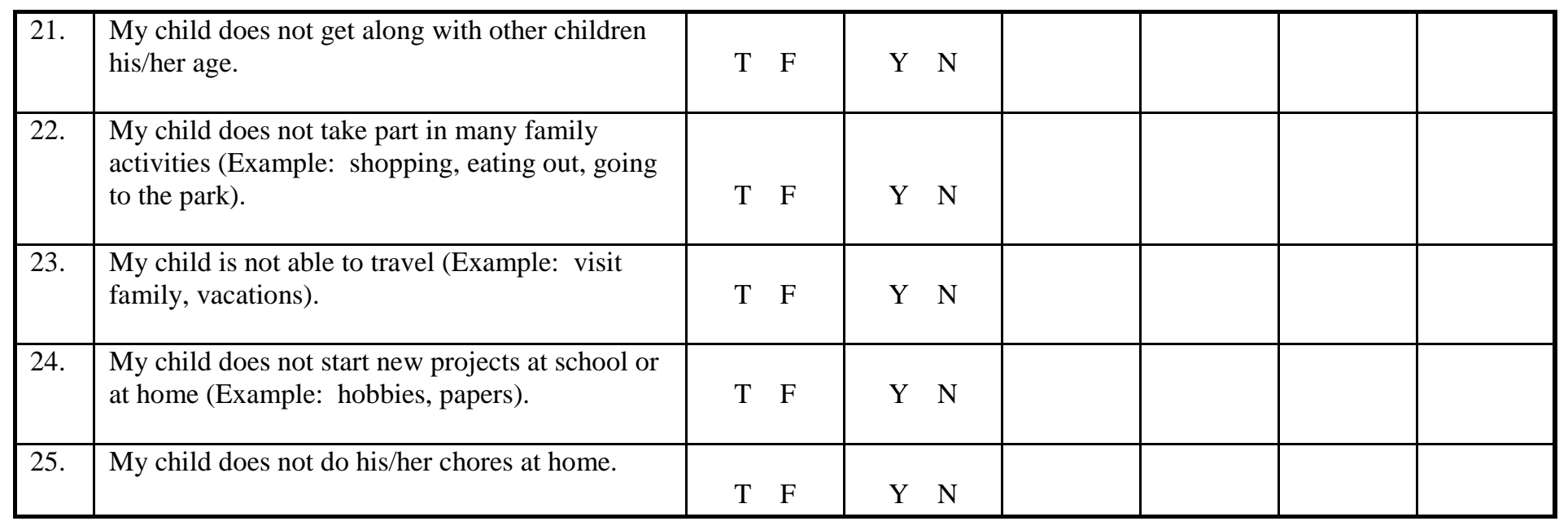

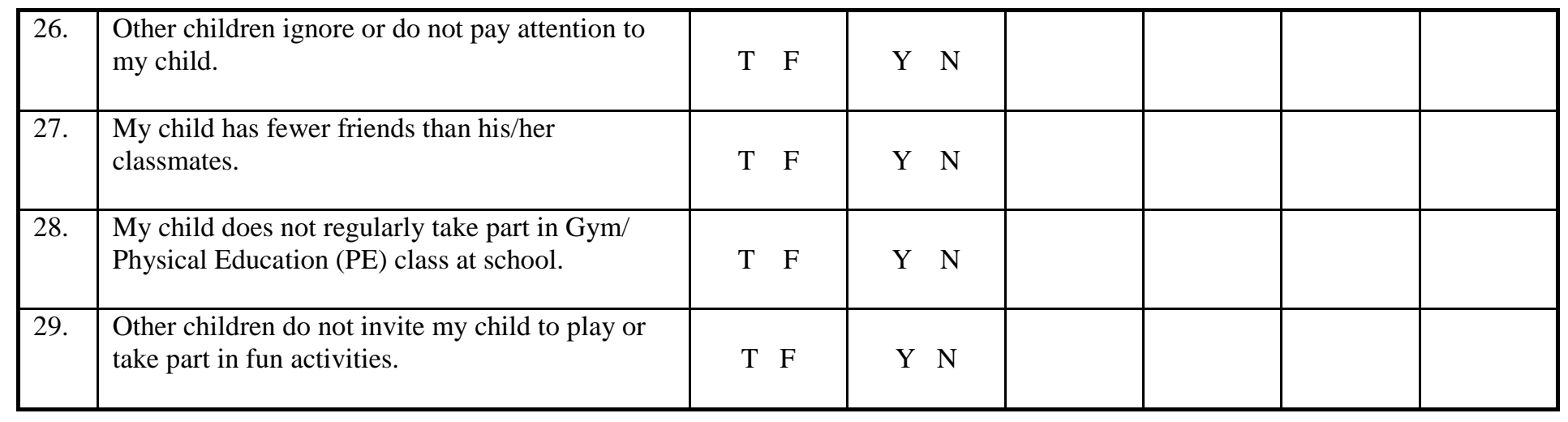


Appendix $C(L C I-Y)$

INSTRUCTION PAGE

PATIENT (YOUTH) FORM

On the next few pages, you will see a list of items asking about your school and social activities.

Read the item. If the statement does NOT describe YOU over the PAST 6 MONTHS, then circle "F" for FALSE. After marking " $F$," do not mark anything else for that item and move to the next question.

SAMPLE ITEMS

HOW UPSET ARE YOU?

Is it

True or because of Not At Just A Pretty Very

False? Injury? All Little Much Much

\begin{tabular}{|l|l|c|c|l|l|l|}
\hline 1. & I do not like to eat vegetables. & $\mathrm{T}(\mathrm{F})$ & $\mathrm{Y} \mathrm{N}$ & & & \\
\hline 2. & I often miss music lessons. & $\mathrm{T} \mathrm{F})$ & $\mathrm{Y} \mathrm{N}$ & & & \\
\hline
\end{tabular}

If the statement describes YOU over the PAST 6 MONTHS and thus is "TRUE," then mark "T" for "TRUE."

After marking "T," move to the next column to the right that asks if the problem is caused by YOUR INJURY

(Brachial Plexus) or something else (like not having money for it, can't get a ride, etc.). Mark "Y" for "YES"

(because of injury) or "N" for "NO" (because of something else).

Then, rate HOW MUCH this problems UPSETS YOU by placing an " $\mathrm{X}$ " in the column that best describes your upset feelings (Not at all, Just a Little, Pretty Much, or Very Much). Please mark " $\mathrm{X}$ " in only ONE of the last four boxes for your rating.

HOW UPSET ARE YOU?

Is it

True or because of Not At Just A Pretty Very

False? Injury? All Little Much Much

\begin{tabular}{|l|l|c|c|c|c|c|}
\hline 1. & I do not like to play games. & (T) & ( & & & \\
\hline 2. & I often miss dentist appointments. & $(\mathrm{T}) \mathrm{F}$ & $\mathrm{Y}(\mathrm{N})$ & $\mathrm{X}$ & & \\
\hline 3. & I do not like to watch TV. & $\mathrm{T}(\mathrm{F})$ & $\mathrm{Y} \mathrm{N}$ & & & \\
\hline
\end{tabular}

Please ask an ADULT for help if you do NOT understand how to fill out this form. 


\section{LIVING WITH A CHRONIC IMPAIRMENT \\ Child/Adolescent Report}

Study ID:

AGE:

GRADE:

SEX: $\quad$ M F

DIRECTIONS: For each question, show if you have had this problem in the past 6 months. If "False", circle "F" under "True or False?" and go to the next question. If "True", circle "T" and then show whether this problem is caused by your injury ( $\mathrm{Y}=\mathrm{Yes} ; \mathrm{N}=\mathrm{No})$. Check how much this problem upsets you by placing an " $\mathrm{X}$ " in the column that best describes your feelings (Not at All, Just a Little, Pretty Much, Very Much). Please check only one of the last four boxes per question.

HOW UPSET ARE YOU BY THIS?

Is it

True or because of Not At Just A Pretty Very

$\underline{\text { False? }} \quad \underline{\text { Injury? }} \quad \underline{\text { All }} \quad \underline{\text { Little }} \quad \underline{\text { Much }} \quad \underline{\text { Much }}$

\begin{tabular}{|l|l|c|c|c|l|l|}
\hline 1. & I miss school. & T F & Y N & & \\
\hline 2. & $\begin{array}{l}\text { I do not take part in school activities (Example: } \\
\text { social groups, pep rallies). }\end{array}$ & T F & Y N & & \\
\hline 3. & $\begin{array}{l}\text { I am left out from activities or games with other } \\
\text { kids. }\end{array}$ & T F & Y N & & \\
\hline 4. & $\begin{array}{l}\text { I do not play team sports (Example: soccer, } \\
\text { football, softball). }\end{array}$ & T F & Y N & & \\
\hline 5. & I have problems making or keeping friends. & T F & Y N & & \\
\hline
\end{tabular}

\begin{tabular}{|l|l|c|c|c|l|l|}
\hline 6. & Other kids tease me about the way I look. & T F & Y N & & & \\
\hline 7. & $\begin{array}{l}\text { I do not take part in outdoor exercise sports } \\
\text { (Example: swimming, bike riding, jogging). }\end{array}$ & T F & Y N & & \\
\hline 8. & Teachers treat me different from my classmates. & T F & Y N & & \\
\hline 9. & $\begin{array}{l}\text { I am not as independent (doing things on my } \\
\text { own) as other kids my age. }\end{array}$ & T F & Y N & & \\
\hline
\end{tabular}


HOW UPSET ARE YOU BY THIS?

Is it

True or because of Not At Just A Pretty Very

False? Injury? $\quad \underline{\text { All }} \quad \underline{\text { Little }}$ Much $\underline{\text { Much }}$

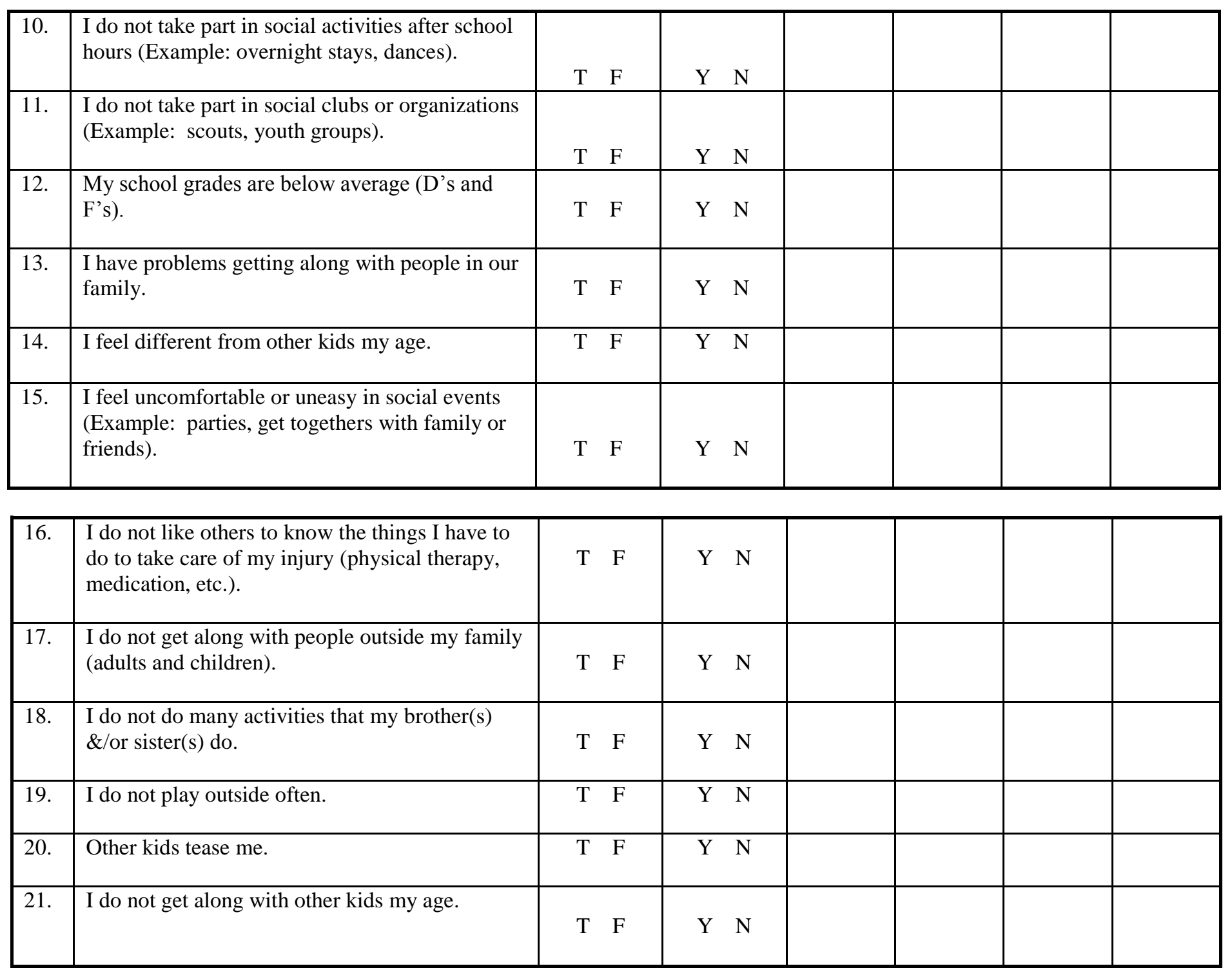


HOW UPSET ARE YOU BY THIS?

Is it

True or because of

False?

because of
Injury?

Not At

Just A

Pretty

Very

All Little $\underline{\text { Much }}$ Much

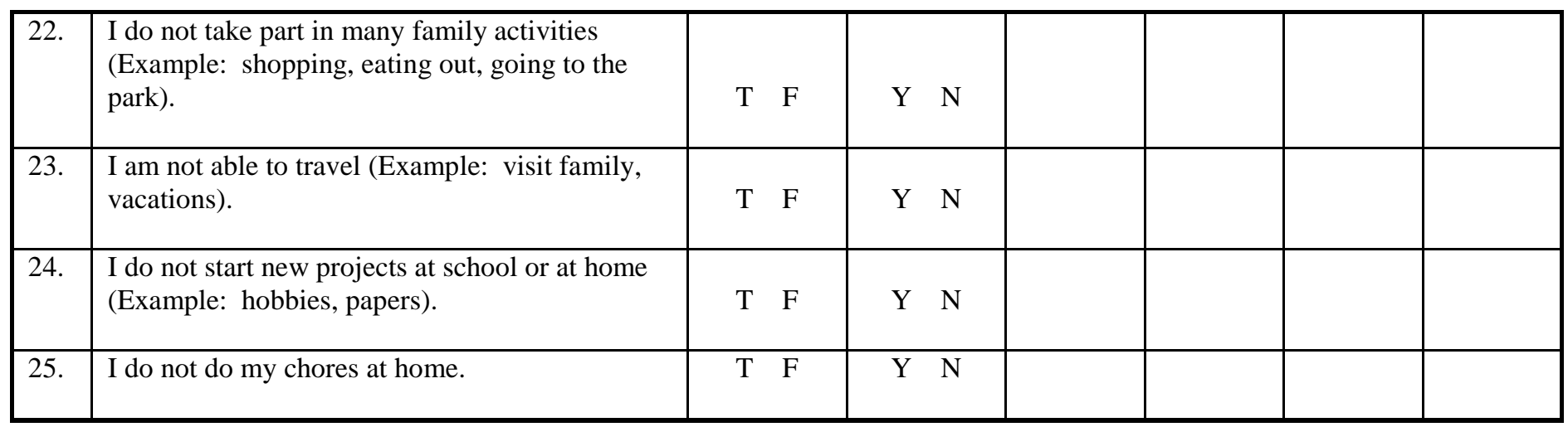

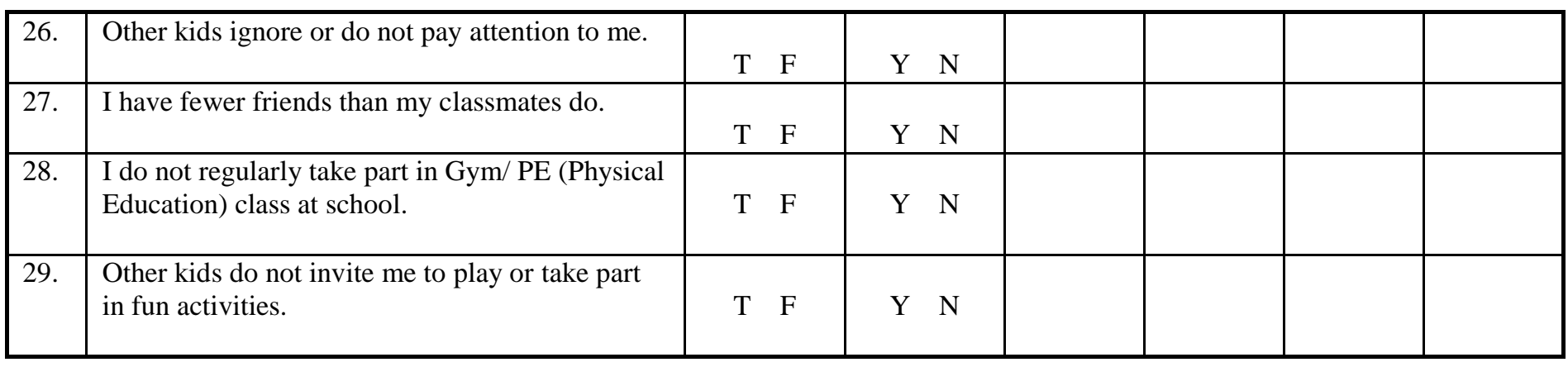




\section{Appendix D (BPSQ-P)}

\section{Brachial Plexus Social Questionnaire - Parent Version}

\section{Study ID:}

Please circle the answer that best describes how true the statement has been for you over the past 6 months.

1. People stare at my child because of his or her arm.

Not at all true Just a little true Pretty much true Very True

2. My child is okay with the way he or she looks.

Not at all true Just a little true Pretty much true Very True

3. Strangers ask my child annoying questions about his or her arm.

Not at all true Just a little true $\quad$ Pretty much true $\quad$ Very True

4. Kids tease my child about the way he or she looks.

Not at all true Just a little true Pretty much true Very True

5. My child is okay with being in public places, like shopping, going to movies, or out to eat.

Not at all true Just a little true Pretty much true Very True

6. Because of my child's arm, kids feel uneasy around him or her.

$\begin{array}{lll}\text { Not at all true Just a little true } \quad \text { Pretty much true } & \text { Very True }\end{array}$

7. My child wishes his or her arm was normal.

Not at all true Just a little true Pretty much true Very True

8. People treat my child differently because of his or her arm injury.

Not at all true Just a little true Pretty much true $\quad$ Very True

9. My child is angry that he or she had an injury to an arm.

Not at all true Just a little true Pretty much true Very True

10. It is hard for my child to have friends or dates because of his or her arm injury.

Not at all true Just a little true Pretty much true Very True 


\section{Appendix E (BPSQ-Y)}

\section{Brachial Plexus Social Questionnaire - Youth Version}

\section{Study ID:}

Please circle the answer that best describes how true the statement has been for you over the past 6 months.

1. People stare at me because of my arm.

Not at all true Just a little true Pretty much true Very True

2. I am okay with the way I look.

Not at all true Just a little true Pretty much true Very True

3. Strangers ask me annoying questions about my arm.

Not at all true Just a little true Pretty much true $\quad$ Very True

4. Kids tease me about the way I look.

Not at all true Just a little true Pretty much true $\quad$ Very True

5. I am okay being in public places, like shopping, going to movies, or out to eat.

Not at all true Just a little true Pretty much true Very True

6. Because of my arm, kids feel uneasy around me.

Not at all true Just a little true Pretty much true Very True

7. I wish my arm was normal.

Not at all true Just a little true Pretty much true Very True

8. People treat me different because of my arm injury.

Not at all true Just a little true Pretty much true Very True

9. I am angry that I have had an injury to my arm.

Not at all true Just a little true Pretty much true Very True

10. It is hard for me to have friends or dates because of my arm injury.

Not at all true Just a little true Pretty much true Very True 
Table 1

Bivariate Associations among Study Variables

\begin{tabular}{|c|c|c|c|c|c|c|c|c|c|c|c|c|}
\hline & Gender & PH-2 & LCI-P & LCI-Y & SSSC-P & SSSC-C & SSSC-T & SSSC-F & KIDCope & BPSQ-P & BPSQ-Y & Injury $^{j}$ \\
\hline Age & -.08 & -.04 & -.11 & .17 & -.02 & -.09 & .04 & -.00 & .00 & -.04 & $.23 *$ & -.11 \\
\hline Gender & & -.07 & .06 & .03 & -.13 & .13 & -.08 & $-.41 * *$ & .14 & .02 & -.00 & -.12 \\
\hline $\mathrm{PH}-2^{\mathrm{a}}$ & & & $-.46^{* *}$ & $-.56^{* *}$ & $-.35^{* * *}$ & $.54 *$ & $-.26^{* *}$ & -.23 & -.01 & $-.36^{* *}$ & $-.54^{* *}$ & .01 \\
\hline LCI-P ${ }^{b}$ & & & & $.52 * *$ & $.34 * *$ & $-.32 * *$ & $.38^{* *}$ & .22 & .03 & $.71 * *$ & $.42 * *$ & .12 \\
\hline LCI-Yc & & & & & $.32 *$ & $-.38^{* *}$ & $.33 * *$ & $.25^{*}$ & .09 & $.49 * *$ & $.62 * *$ & -.01 \\
\hline SSSC-P ${ }^{d}$ & & & & & & $-.46^{* * *}$ & $.52 * *$ & $.46 * *$ & -.19 & .17 & $.30 * *$ & .12 \\
\hline SSSC-C ${ }^{e}$ & & & & & & & $-.54^{* *}$ & $-.42 * *$ & .16 & $-.33 * *$ & $.52^{* *}$ & .03 \\
\hline SSSC-T ${ }^{f}$ & & & & & & & & $.46^{* * *}$ & -.01 & $.32 * *$ & $.34 * *$ & .12 \\
\hline SSSC-F & & & & & & & & & -.19 & $.25 *$ & .23 & .15 \\
\hline KIDCope & & & & & & & & & & .19 & -.11 & .06 \\
\hline BPSQ-P ${ }^{h}$ & & & & & & & & & & & $.52 * *$ & .13 \\
\hline BPSQ- $Y^{\mathrm{i}}$ & & & & & & & & & & & & -.16 \\
\hline
\end{tabular}

${ }^{\mathrm{a}}$ Piers-Harris $2^{\text {nd }}$ Edition; ${ }^{\mathrm{b}}$ Living with a Chronic Impairment - Parent Version; ${ }^{\mathrm{c}}$ Living with a

Chronic Impairment - Youth Version; ${ }^{\mathrm{d}}$ Social Support Scale for Children - Parent domain; ${ }^{\mathrm{e}}$

Social Support Scale for Children - Classmate domain; ${ }^{\mathrm{f}}$ Social Support Scale for Children -

Teacher domain; ${ }^{\mathrm{g}}$ Social Support Scale for Children - Close Friend domain; ${ }^{\mathrm{h}}$ Brachial Plexus

Social Questionnaire-Parent Report; ${ }^{\mathrm{i}}$ Brachial Plexus Social Questionnaire-Youth Report; ${ }^{\mathrm{j}}$

Injury Severity 
Table 2

Means and Standard Deviations of Psychosocial Measures

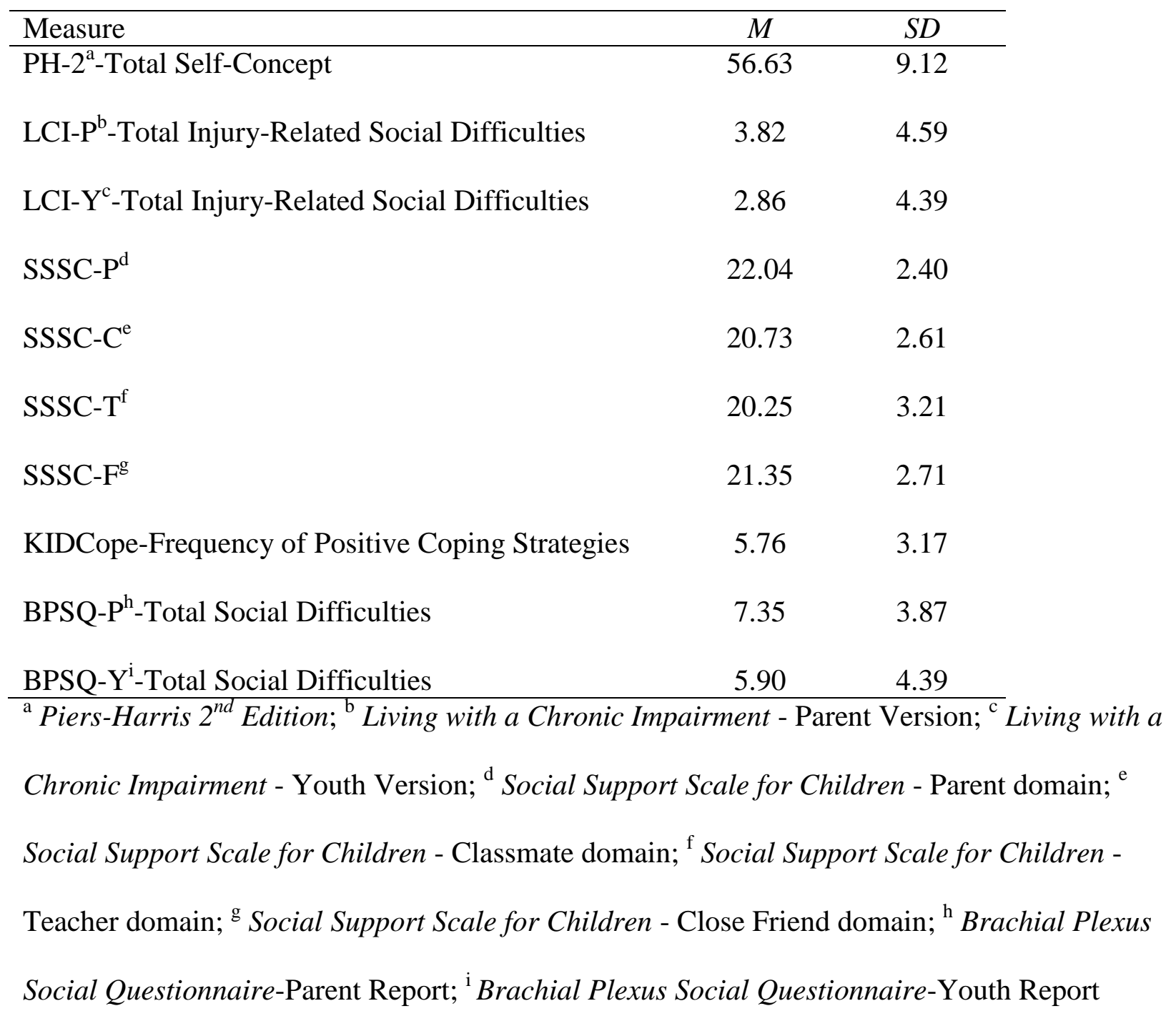


Table 3

Means and Standard Deviations of the Living with a Chronic Impairment-Parent (LCI-P) and Child (LCI-Y) Versions across Various Samples

\begin{tabular}{lccc}
\hline Measure & OBPI $^{\mathrm{a}}$ & Chronic Illness $^{\mathrm{b}}$ & Burn Injuries $^{\mathrm{c}}$ \\
\hline LCI-P & $M(S D)$ & $M(S D)$ & $M(S D)$ \\
LCI-Y & $3.82(4.59)$ & $7.80(11.70)$ & $2.40(4.50)$ \\
& $2.86(4.39)$ & $4.40(7.00)$ & $0.80(3.10)$ \\
\hline
\end{tabular}

${ }^{\mathrm{a}}$ Current study sample; ${ }^{\mathrm{b}}$ Adams et al., 2002; ${ }^{\mathrm{c}}$ Piazza-Waggoner et al., 2004 
Table 4

Means and Standard Deviations of the Social Support Scale for Children (SSSC) Total Domain Scores across Two Samples

\begin{tabular}{lcc}
\hline SSSC Domain & OBPI $^{\mathrm{a}}$ & $\begin{array}{c}\text { Burn Injuries } \\
\text { b }\end{array}$ \\
\hline Parent & $22.04(2.40)$ & $16.00(2.00)$ \\
Classmate & $20.73(2.61)$ & $16.30(2.20)$ \\
Teacher & $20.25(3.21)$ & $15.90(2.40)$ \\
Close Friend & $21.35(2.71)$ & $16.20(2.40)$
\end{tabular}

${ }^{\mathrm{a}}$ Current study sample; ${ }^{\mathrm{b}}$ Girolami, 2005 
Table 5

Means and Standard Deviations for Mean Item Scores by Domain on the Social Support Scale for Children (SSSC) across Two Samples

\begin{tabular}{lcc}
\hline SSSC Domain & $\begin{array}{c}\text { OBPI }^{\mathrm{a}} \\
M(S D)\end{array}$ & $\begin{array}{c}\text { Congenital Limb Deficiencies }^{\mathrm{b}} \\
M(S D)\end{array}$ \\
\hline Parent & $3.61(0.58)$ & $3.51(0.52)$ \\
Classmate & $3.44(0.48)$ & $3.30(0.60)$ \\
Teacher & $3.39(0.60)$ & $3.26(0.78)$ \\
Close Friend & $3.57(0.50)$ & $3.39(0.55)$
\end{tabular}

${ }^{\mathrm{a}}$ Current study sample; ${ }^{\mathrm{b}}$ Varni et al., 1992 
Table 6

Standardized Coefficients ( $\beta$ ) and Significance Levels (p-value) for Step Two of the Multiple

Regression Analysis: Youth-Reported Social Difficulties Predicted from Four Domains of Social

Support, Frequency of Positive Coping Strategies, Injury Severity, and Age

\begin{tabular}{|c|c|c|}
\hline Predictor & $\beta$ & $p$-value \\
\hline $\mathrm{SSSC}^{-\mathrm{C}^{\mathrm{a}}}$ & -.206 & .188 \\
\hline SSSC-P ${ }^{b}$ & .128 & .400 \\
\hline SSSC-T & .032 & .847 \\
\hline SSSC-F ${ }^{\mathrm{d}}$ & .152 & .301 \\
\hline Injury Severity & .085 & .507 \\
\hline KIDCope $^{\mathrm{e}}$ & .128 & .312 \\
\hline Age & .199 & .108 \\
\hline SSSC-P X Age & .258 & .047 \\
\hline
\end{tabular}


Table 7

Brachial Plexus Social Questionnaire Parent Version (BPSQ-P) Item-to-Total Correlations

\begin{tabular}{lc}
\hline Item & $r$ \\
\hline People stare at my child because of his/her arm. & .34 \\
My child is okay with the way he/she looks. & .41 \\
Strangers ask my child annoying questions about his/her arm. & .45 \\
Kids tease my child about the way he/she looks. & .50 \\
My child is okay with being in public places, like shopping, going to the movies, or & .15 \\
out to eat. & .58 \\
Because of my child's arm, kids feel uneasy around him/her. & .39 \\
My child wishes his/her arm was normal. & .54 \\
People treat my child differently because of his/her arm. & .44 \\
My child is angry that he/she had an injury to his/her arm. & .46 \\
\hline
\end{tabular}


Table 8

Brachial Plexus Social Questionnaire Youth Version (BPSQ-Y) Item-to-Total Correlations

\begin{tabular}{lc}
\hline Item & $r$ \\
\hline People stare at me because of my arm. & .51
\end{tabular}

$\begin{array}{ll}\text { I am okay with the way I look. } & .48\end{array}$

Strangers ask me annoying questions about my arm. $\quad .44$

Kids tease me about the way I look. $\quad .46$

I am okay with being in public places, like shopping, going to the movies, or out to eat. $\quad .00$

Because of my arm, kids feel uneasy around me.

$\begin{array}{ll}\text { I wish my arm was normal. } & .48\end{array}$

People treat me differently because of my arm.

I am angry that I have had an injury to my arm. $\quad .53$

It is hard for me to have friends or dates because of my arm injury. $\quad .22$ 
Figure 1.

Demonstration of Potential Interaction between Age and Perceived Social Support from Parents on Youth-Reported Social Functioning

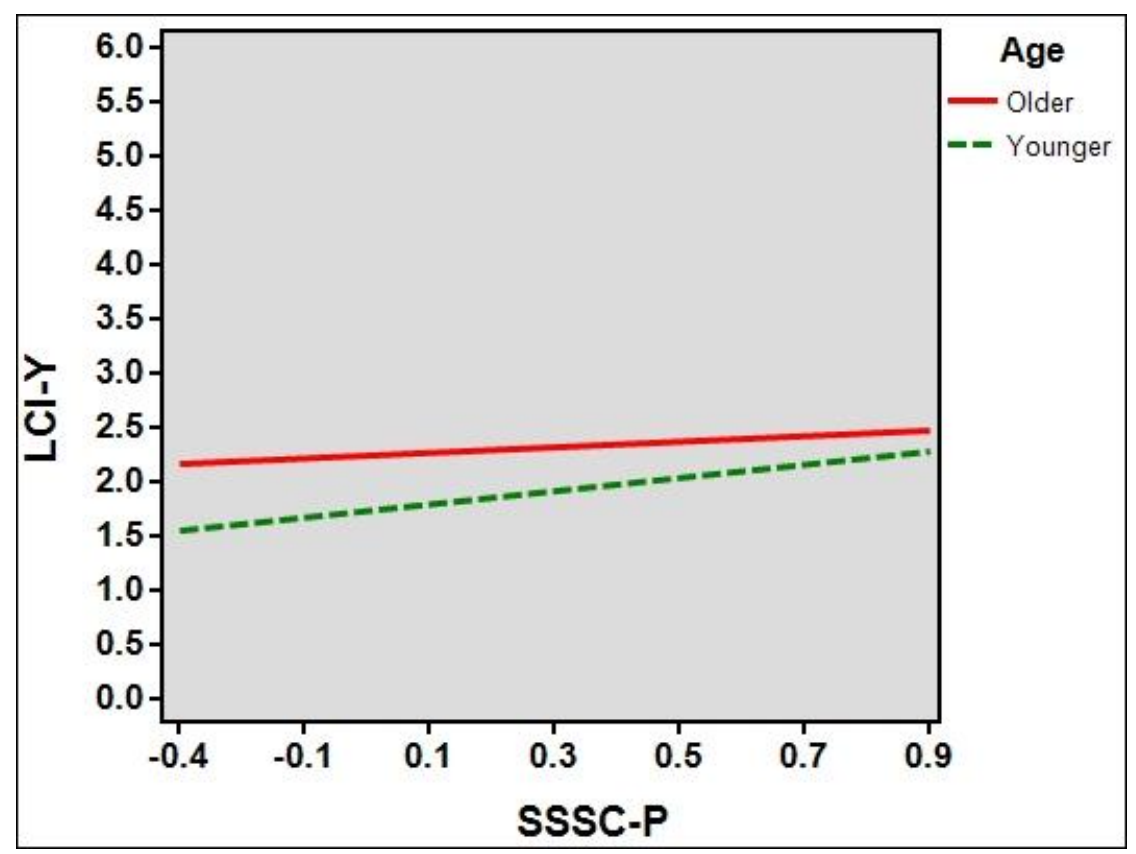

Note. Simple slopes presented for +/- 1 standard deviation away from the mean (i.e., older adolescents $=+1$ standard deviation; younger adolescents $=-1$ standard deviation). Simple slopes also were explored for $+/-2$ and 3 standard deviations away from the mean; these associations were non-significant. 
